\title{
Experimental superheating of water and aqueous solutions
}

\author{
Kirill I. Shmulovich ${ }^{\mathrm{a}}$ Lionel Mercury ${ }^{\mathrm{b}, \mathrm{c},}$ Régis Thiéry $^{\mathrm{d}}$ Claire Ramboz $^{\mathrm{b}}$ and Mouna El \\ Mekki $^{\text {b }}$
}

${ }^{\mathrm{a}}$ Institute of Experimental Mineralogy, Russian Academy of Science, 142432 Chernogolovka, Russia

${ }^{\mathrm{b}}$ Institut des Sciences de la Terre d'Orléans, UMR 6113 CNRS/Universités Orléans-Tours, 1A rue de la Férollerie, 45071 Orléans Cedex, France

‘UMR-CNRS 8148 “IDES”, Université Paris-Sud, bat. 504, 91405 Orsay, France

${ }^{\mathrm{d}}$ Laboratoire Magmas et Volcans, UMR 6524, CNRS/Clermont Université, 5 rue Kessler, 63038 Clermont-Ferrand Cedex, France

\begin{abstract}
The metastable superheated solutions are liquids in transitory thermodynamic equilibrium inside the stability domain of their vapor (whatever the temperature is). Some natural contexts should allow the superheating of natural aqueous solutions, like the soil capillarity (low $T$ superheating), certain continental and submarine geysers (high $T$ superheating), or even the water state in very arid environments like the Mars subsurface (low $T$ ) or the deep crustal rocks (high $T$ ). The present paper reports experimental measurements on the superheating range of aqueous solutions contained in quartz as fluid inclusions (Synthetic Fluid Inclusion Technique, SFIT) and brought to superheating state by isochoric cooling. About 40 samples were synthetized at $0.75 \mathrm{GPa}$ and $530-700{ }^{\circ} \mathrm{C}$ with internally-heated autoclaves. Nine hundred and sixty-seven inclusions were studied by micro-thermometry, including measuring the temperatures of homogenization (Th: $L+V \rightarrow L$ ) and vapor bubbles nucleation (Tn:

$L \rightarrow L+V$ ). The Th-Tn difference corresponds to the intensity of superheating that the trapped liquid can undergo and can be translated into liquid pressure (existing just before nucleation occurs at $\mathrm{Tn}$ ) by an equation of state. Pure water $\left(840-935 \mathrm{~kg} \mathrm{~m}^{-3}\right)$, dilute $\mathrm{NaOH}$ solutions ( 0.1 and $\left.0.5 \mathrm{~mol} \mathrm{~kg}^{-1}\right), \mathrm{NaCl}, \mathrm{CaCl}_{2}$ and $\mathrm{CsCl}$ solutions ( 1 and $5 \mathrm{~mol} \mathrm{~kg}^{-1}$ ) demonstrated a surprising ability to undergo tensile stress. The highest tension ever recorded to the best of our knowledge $\left(-146 \mathrm{MPa}, 100{ }^{\circ} \mathrm{C}\right)$ is attained in a $5 \mathrm{~m} \mathrm{CaCl}_{2}$ inclusion trapped in quartz matrix, while $\mathrm{CsCl}$ solutions qualitatively show still better superheating efficiency. These observations are discussed with regards to the quality of the inner surface of inclusion surfaces (high $P-T$ synthesis conditions) and to the intrinsic cohesion of liquids (thermodynamic and kinetic spinodal). This study demonstrates that natural solutions can reach high levels of superheating, that are accompanied by strong changes of their physicochemical properties.
\end{abstract}




\section{Introduction}

Superheating is a form of metastability experienced by condensed matter. It corresponds to a stretched (or tensile) state, where the matter undergoes a stretching stress without losing the cohesion of its structure. In the case of solid metals, such stress is a classic mechanical test of the alloy quality and is made by direct traction of a metal sheet by special clamps (e.g. ISO6892 standard), or by indirect (Brazilian) tensile tests (e.g. ASTM D3967-05 standard). Liquids, though condensed substances, (i) cannot be submitted to traction by mechanical means and (ii) transform into vapor when the tensile force exceeds its cohesion (liquid-tovapor transition). In others words, superheated liquid is metastable with respect to its vapor, and bringing a liquid in the stability domain of its vapor causes this liquid to superheat. Isothermal decompression, isobaric heating, as well as isochoric cooling may produce superheated liquid (Fig. 1). In the case of isochoric cooling, as the isochores are very steep and the saturation curve is very flat in the pressure-temperature $(P-T)$ plot (Fig. 1), a slight cooling below $L-V$ equilibrium $\left(\mathrm{Th}-\mathrm{Tn}=5-10^{\circ} \mathrm{C}\right.$, for instance; Th the temperature at saturation, Tn that at nucleation) brings the occluded liquid in the area of liquid negative pressures, i.e. under tension.

A metastable state is at intrinsic thermodynamic equilibrium but has a limited lifetime. An isolated liquid (i.e. in the absence of any heat, work and matter exchange with the exterior) is at its equilibrium state when its entropy is maximal, or equivalently its internal energy is minimal. As such, any internal fluctuation must result to a positive or a null variation of its internal energy (Debenedetti, 1996). This consequence of the second law of thermodynamics can be formulated by means of the two following conditions:

$$
\begin{aligned}
& \text { thermal cendibion: }\left(\frac{\partial T}{\partial s}\right)_{F}=\frac{T}{C_{g}}>0 \\
& \text { mechanical condition : }-\left(\frac{\partial P}{\partial t}\right)_{\tau}=\frac{1}{t \cdot K_{T}}>0
\end{aligned}
$$

where $T$ is the temperature, $s$ is the specific entropy, $C_{p}$ is the isobaric heat capacity, $v$ is the specific volume, $P$ is the pressure, $K_{T}$ is the isothermal compressibility.

When (1a) and (1b) become nil, the thermodynamic limit of metastability is reached: this is the location of the so-called spinodal curve which originates at the critical point and extends down into the (liquid) negative pressure region (Fig. 1). In the spinodal state, the usual matter separation of nucleation-phase growth is replaced by the faster and more efficient process of spinodal decomposition (Debenedetti, 1996) meaning that the approach of the liquid to the spinodal conditions is synonym to explosive vaporization ([Thiéry and Mercury, 2009-a] and [Thiéry and Mercury, 2009-b]). By contrast, at weak superheating degrees, the nucleation of bubbles is a slow process which must be activated to occur. Under higher superheating degrees, the energetic barrier of the nucleation becomes of the same order of magnitude than the molecular fluctuations. Thus, bubble nucleation becomes an active and spontaneous mechanism. Kiselev and Ely (2001) have calculated precisely the $P-T$ conditions of this change of nucleation regime for water, introducing the notion of kinetic spinodal. This curve mimics the trend of thermodynamic liquid spinodal curve (but is shifted to lower temperatures in a $P-T$ plot) (Fig. 1). In the same way, the concept of spinodals can be generalized fruitfully to solids, which exhibit explosive fragmentations (the so-called spallation), when they are 
submitted to sudden and strong negative pressures by means of shockwaves (Imre et al., 2008).

The geological significance of superheating applies to two distinct fields. Firstly, the superheating produces liquids which are susceptible to vaporize explosively. This occurs in hydrothermal and volcanic environments (especially phreato-magmatic ones), where strong thermal gradients, cold-hot mixing, or rapid decompression generate strong superheating degrees ([Thiéry and Mercury, 2009-a] and [Thiéry and Mercury, 2009-b]). Secondly, superheating modifies the thermodynamic properties of liquid water and thus its solvent properties with respect to gases and solids ([Zilberbrand, 1997], [Zilberbrand, 1999], [Mercury and Tardy, 1997a], [Mercury and Tardy, 1997b], [Mercury and Tardy, 2001] and [Mercury et al., 2003]). Therefore, the gas-solid-solution equilibria associated with superheated solutions at low $T$ (soil capillarity; [Mercury et al., 2004], [Lassin et al., 2005] and [Pettenati et al., 2008]) and high $T$ (geothermal or hydrothermal environments, especially associated with ore deposits processes), may be strongly modified.

\section{Superheating features and previous experiments}

The first observations of superheated liquids trace back to the 17th century. Several reviews have given the main features and steps on historical perspective on this concept ([Hayward, 1971], [Apfel, 1972], [Kell, 1983] and [Imre and Van Hook, 1998]) as well as on its thermodynamic foundations (Imre et al., 1998).

Since the first observations of Huygens in 1661-1662 which were qualitative but still quite demonstrative (Kell, 1983), many experiments were conducted to measure various ranges of superheating in liquids. A key feature of the superheating phenomenon is the tensile state of the liquid, which often corresponds to a negative liquid pressure. This is a counter-intuitive concept as long as pressure is thought as the applied force exerted by moving particles per unit area which is an often-used model of the gas pressure. In this latter sense, there is a close proportionality between density and pressure, and a negative gas pressure has obviously no physical meaning. In the case of condensed matter, and recalling that a force is primarily a vector quantity, the intrinsic cohesion of the matter makes it able to sustain a force tending to distort the structure. This is readily understood with a solid, when mechanical clamps are used to exert a tensile force upon it until it breaks out (defining its maximal tensile force). This is more difficult to understand for liquids which cannot be directly clamped in order to be stretched. The only way to create tensile state in a liquid is to superheat it enough for its pressure to become negative, which can be achieved by putting the liquid below its $(P, T)$ saturation conditions.

A superheated liquid is metastable with respect to its vapor and therefore able to nucleate at any moment. During the 18th century, Rev. Dayton already noticed how easy is a liquid to superheat and the associated explosive hazard (Dayton, 1739). Nowadays, this is a wellknown class of industrial spills accidents, connected to the Boiling Liquid Expanding vapor Explosion (BLEVE) type (e.g. Reid, 1976). But superheated liquids also have useful properties and applications, such as their solvent capabilities which make them the "ultimate green solvent for separation science" (e.g. [Smith, 2006] and [Chienthavorn and Su-in, 2006]).

Superheated liquids are relevant to two geological contexts. Firstly, capillary (or pendular) water in non-saturated soils is superheated, and with a lifetime considerably longer than any 
other superheated liquid owing to the stabilizing effect of the mechanical bridging between two solids (Young-Laplace condition; e.g., Mercury and Tardy, 2001). This is lowtemperature superheating. Secondly, systems having strong thermal anomalies, such as continental or submarine geysers, or where hot magma and cold water come suddenly into contact (phreato-magmatic eruptions), are, at least partly, functioning with a superheating component ([Steinberg et al., 1982], [Ramboz and Danis, 1990] and [Thiéry and Mercury, 2009-a]). These are high-temperature superheating processes.

In terms of experimental measurements, after the pioneering works of Briggs (e.g. [Briggs, 1950] and [Briggs, 1955]), a Russian team under Skripov's leadership made substantial progresses in this area (e.g. Skripov, 1974), followed by others teams (e.g. Trevena, 1987). Many techniques have been used at various times, as reviewed by Caupin and Herbert (2006). To summarize, the authors distinguished two groups of results. The first, carried out using a large variety of techniques (Berthelot tubes, centrifugation of a capillary Z-tube, shock waves, acoustic cavitation, ...), observed a maximum experimental tensile stress of around -20 , $-30 \mathrm{MPa}$, depending on temperature. Many published results exceeded these proposed values, but Caupin and Herbert (2006) argued that these experiments were fraught with mistakes. The second group corresponds to only one technique, that is the isochoric cooling of natural or synthetic fluid inclusions below the $(P, T)$ conditions of Liquid-Vapor $(L V)$ saturation (Fig. 1). Pure water or aqueous solutions trapped in a solid matrix (quartz in general) were demonstrated to superheat up to very high tensions (e.g. [Green et al., 1990], [Zheng et al., 1991] and [Alvarenga et al., 1993]) with corresponding changes of phase equilibria (Roedder, 1967). The liquid tension is calculated extrapolating the equation of state (EoS) either from a micro-thermometric measurement of the homogenization and nucleation temperatures (see below) (e.g. [Green et al., 1990] and [Zheng et al., 1991]), or from spectroscopic (Brillouin) measurements of the speed of sound (Alvarenga et al., 1993).

A key difference between these two classes of techniques is the manner by which the liquid volume occupies the experimental cell. In the case of dynamic/capillary techniques there is only one water volume, so that the first nucleation event causes the entire volume to boil. In the case of inclusion samples, the liquid is dispersed as numerous micrometric cavities in the same solid fragment, and the vapor nucleates at $P, T$ conditions specific to each inclusion.

\section{Experimental techniques}

\subsection{Procedures and apparatus}

Most of the fluid inclusions were synthetized in internally-heated pressure vessels (IHPV, or "gas bombs") at the University of Edinburgh (Synthetic Fluid Inclusion, or SFI). The hydrothermal syntheses were performed at $750 \mathrm{MPa}$ in the $530-700{ }^{\circ} \mathrm{C}$ range, during $8-$ 13 days. Two methods were used: thermal crack sealing (Bodnar and Sterner, 1985) and trapping of inclusions during overgrow from the original quartz seed (Shmulovich and Graham, 2004). The first method gives samples with chain-like or isolated inclusions, usually formless or having "ameba"-like shape, except in runs at high temperature and with alkali solutions. The second method produces inclusions with edges, faces and corners, sometimes having even the "negative shape" of quartz. However, in this latter case, inclusions are often surrounded by an overgrowth rim where many very small inclusions form an "halo", which makes it difficult to measure the temperature of the vapor-to-liquid transition (Th) with reasonable precision when the disappearing bubble becomes too small. In contrast, the 
temperature of the liquid-to-vapor transition (Tn) is always precisely measured because nucleating bubble(s) have sufficiently large size.

For each run, the IHPV is loaded with 3 or 4 Pt-capsules filled with quartz $(2 \times 2 \times 12 \mathrm{~mm}$, with the longest dimension parallel to the quartz $c$-axis), the selected liquid (pure water or aqueous solutions at the chosen concentration) and amorphous silica. Two types of quartz pieces were used: (1) thermally-cracked quartz which will be healed at high $P-T$ conditions owing to the presence of amorphous silica in the capsule solution; (2) clean quartz overgrown by new materials owing to a thermal gradient of $5^{\circ} \mathrm{C}$ along the seed. This latter method produces a lot of inclusions in the same plane (same distance to the sample surfaces), which is an advantage of this technique. Its drawback is that there are so many inclusions that it is difficult to see what happens in the focused inclusion of interest. Sealed capsules were placed on a Ta or Mo holder wherein the temperature is controlled by two Pt-Pt $13 \% \mathrm{Rh}$ thermocouples (certified to $\pm 1^{\circ} \mathrm{C}$ ). Pressure was measured by manganin gauges after calibration at the mercury melting point, and checked by a Bourdon gauge up to $200 \mathrm{MPa}$. Since the IHPV displays large enough thermal gradient and suffers from constant leakage (approx. 15-17 MPa/day, compensated by intensifier) through the week experiment, each run contained only 3 or 4 capsules, one with pure water (as a standard) and the others with different solutions. Therefore, the compared behavior makes more sense when done between samples coming from the same run, as these were synthetized at the same conditions and duration.

Once the required synthesis time elapsed, the power supply was turned off and temperature decreased to $100^{\circ} \mathrm{C}$ in one minute, while pressure was decreased by intensifier to $300 \mathrm{MPa}$. In a second step, the IHPV was allowed to cool down on its own to room temperature and opened to recover the capsules.

Comparisons of pure water densities deduced from the Th measurements using the IAPWS-95 EoS (Wagner and Pruss, 2002) demonstrate systematic deviations with respect to what was expected from the nominal $(P, T)$ run parameters. Pressure could be smaller and/or temperature higher to fit the measured densities. As mentioned above, the pressure had to be corrected on a daily basis, so that the actual average pressure was somewhere between 730 and $750 \mathrm{MPa}$. In addition, the capsules were lying on the holder wall while the thermocouples measured the temperature of the argon atmosphere between capsules. The real temperature in capsule is expected to be higher due to conductive heat exchange. Altogether, we estimate that the actual temperature is $20-30{ }^{\circ} \mathrm{C}$ higher than the nominal temperature.

\subsection{Preparation of samples and micro-thermometry}

Quartz seeds containing the targeted liquids and sealed at hydrothermal conditions were cleaned with water, dried and fixed with Canadian balsam inside glass tubes. The tubes were cut as 5-7 discs of 0.6-0.7 mm thickness, after which each disc was carefully doubly polished. The final thickness was around $500 \mu \mathrm{m}$. A washing procedure in acetone and ultrasonic bath was applied three times.

Usually, two to three polished samples were selected from each $P-T$ run wherein many inclusions were explored by micro-thermometry. Depending on the sample, between ten up to more than 50 inclusions could be analyzed (Table 1, last column " $n$ "). 
The micro-thermometric procedure (Fig. 1) consists of progressive heating on a "Linkam" stage of one sample, in general containing initially the biphasic liquid + vapor assemblage $(L+V)$. The first step corresponds to the displacement along the saturation line, with a progressive change of temperature, liquid density and bubble pressure (A-B path, Fig. 1). At a particular density, the trapped liquid invades the whole inclusion space: there is no more vapor and the inclusion is said to be homogenized (B point, Fig. 1). The temperature at which this filling appears is then the homogenization temperature, noted Th. Just before Th, vapor bubble is so small that it can move along the minor thermal gradients within the inclusion, which results in the appearance of a mobile shadow. Further heating drives the $P-T$ conditions in the inclusion along the isochore inside the stable domain of liquid (B-C path, Fig. 1). Special care must be taken because overheating above Th may lead to the decrepitation of the inclusion, especially at overheating greater than $30{ }^{\circ} \mathrm{C}$ (but $10{ }^{\circ} \mathrm{C}$ can be sufficient; see also Bodnar et al., 1989): this depends also on (at least) the shape of the inclusion, its thickness and the distance to neighboring inclusions. One decrepitation event can be detected when a further Th measurement on the same inclusion increases by more than $1{ }^{\circ} \mathrm{C}$ with respect to antecedent measurements. In this case, we assume that the inclusion suffered a partial water leakage in small quantity (increasing quartz dislocations, formation of optically invisible micro-cracks) which decreased a little the liquid density ([Bakker and Jansen, 1991] and [Bakker and Jansen, 1994]).

The second step is the progressive cooling of the sample, which follows the isochoric path as long as the inclusion remains homogeneously filled with liquid $(\mathrm{C}-\mathrm{D}$ path without nucleation at B, Fig. 1). The temperature of the bubble appearance is called the nucleation temperature (Tn) and is always located within the tensile domain: nucleation in fluid inclusions often disobeys the saturation conditions.

The key feature of "bubble or not bubble" is closely examined under microscope, and needs great care and experience since the nucleation near Th can occur as minute bubbles which can be very easily missed out. In some inclusions, Th was not measured as the vapor bubble moved to shadowed parts which does not allow to detect unambiguously the disappearance of the bubble (especially with overgrown sample, see above). The cycling technique (Goldstein and Reynolds, 1994) could probably improve our measurements in these special circumstances. By comparison, the bubble event at Tn produces either one-two big bubbles or a large amount of intermediate-sized bubbles which explode violently. An illustrative movie displaying intensive boiling in one inclusion $\left(5 \mathrm{~m} \mathrm{NaCl}\right.$; $\mathrm{Th}=221^{\circ} \mathrm{C}$; $\left.\mathrm{Th}-\mathrm{Tn}=51^{\circ} \mathrm{C}\right)$ is available at http://www.iem.ac.ru/staff/kiril.

The influence of the cooling/heating rate on the Tn and Th temperatures was tested as well as that of the distance between the heated/cooled sample surface and the focused inclusion (role of the thermal gradient). The reproducibility was assessed by making seven measurements of the same inclusion $(100 \times 8 \mu \mathrm{m}$ visible size $)$ in sample 23 using heating/cooling rates varying from 1 to $5{ }^{\circ} \mathrm{C} / \mathrm{min}$. Th varied from 200.7 to $200.9^{\circ} \mathrm{C}$ and $\mathrm{Tn}$ from 146.7 to $146.9^{\circ} \mathrm{C}$, for a Th-Tn difference at $51 \pm 1{ }^{\circ} \mathrm{C}$. This shows that the heating/cooling rate has a negligible influence on the reported measurements.

Finally, the measurements were performed on a Linkam stage at three different laboratories. Samples labeled 4-36 were studied at the School of Earth Sciences of Edinburgh where the measurement cell is equipped with a silver cover which strongly decreases any $\mathrm{T}$ gradient in the cell. Samples 37-42 (and also a 62 one) were studied at the Institute of Experimental Mineralogy in Chernogolovka, and also at the Institute of Earth Sciences of Orléans. In this 
latter case, the Linkam stage (without the silver cover) was calibrated with special ceramics, so that the data were corrected for the known gradient (around $4-5^{\circ} \mathrm{C}$, approx. similar for Th and Tn). The data from Edinburgh and that corrected from the measurements made in Orleans coincide within the limits of experimental precision.

\section{Results}

The data collected in this study (Table 1, Fig. 2, Fig. 3, Fig. 4, Fig. 5 and Fig. 6) are displayed following two strategies. First are shown the histogram distributions of both the Th and the $\mathrm{Th}-\mathrm{Tn}$ trends for each type of liquid. These can be considered as the raw micro-thermometric data. We also show the corresponding phase $P-T$ diagram after use of a suitable EoS. This procedure bears on two explicit assumptions: (1) the cooling from Th to Tn follows an isochoric path; (2) the EoS can be extrapolated in the superheated domain

\subsection{Pure water}

The histogram distribution (Fig. 2a) shows the large scatter of nucleation conditions for one sample. The Th distribution shows a usual $2-3{ }^{\circ} \mathrm{C}$ standard deviation and the average values can be considered characteristic of the behavior at the mean liquid density. The random deviation can be accounted for by (1) the thermal gradients in the holders inside the IHPV and (2) those associated with the position of the sampled inclusions with respect to the heat source and the thermocouples inside the Linkam stage. The deviation may also relate to the size of the inclusion, which can be assessed measuring the size of the gas bubble at ambient conditions. The volume of liquid is then deduced from the following relation:

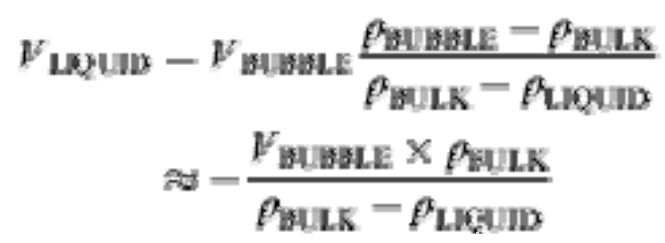

where $\rho_{\mathrm{BULK}}$ is the density at homogenization (deduced by the saturation curve and the Th measurement), and $\rho_{\text {LIQUID }}$ is the density of the liquid at ambient temperature.

The total volume of inclusion is the sum of the two volumes, $V_{\text {LIQUID }}$ and $V_{\text {BUBBLE. The }}$ correlation between the size and Th was established on seven samples: 14-15, 18, 31, 34, 37 and 40, with twenty or more inclusions analyzed per sample. However, the relationships show weak trends with correlation factors $r^{2}$ lower than 0.5 . Obviously, other parameters, like those quoted above and perhaps some other, are acting in addition to the size effect.

The variations of Tn are much larger and can be accounted for by different reasons, acting in combination or alone. The first cause may be related to the type of nucleation: homogeneous nucleation requires enough tension to break the liquid structure, whereas for heterogeneous nucleation, the presence of one singularity on the wall surface and/or one impurity throughout the liquid itself can trigger bubble formation, even at small or medium tension. Secondly, the dispersion of the Tn can be caused by the deformation of the solid matrix during cooling can be (at least partly) plastic, changing liquid density and so the Tn. In this case the cooling is no longer isochoric (at least not exactly isochoric). However, this interpretation is not sufficient to explain the Tn discrepancies of fluid inclusions in a same sample, which are supposed to follow the same $P-T$ path. Thirdly, another effect is the possible (irreversible) deformation of 
the crystal cavity itself due to the increasing liquid stretching under cooling. The capability of stretched liquids to deform the solid cavities has been already proposed for quartz fluid inclusions (Alvarenga et al., 1993), and directly observed inside silicon nano-channels (Tas et al., 2003). Fourthly, the Tn data scattering can also arise from differences in the laboratory conditions of measurements (silver cover or not, special cell, thermal stability, ...) and from the thermal gradient upon the Linkam stage (also depending on the local set-up). However, these latter are random errors, which act similarly on both Th and Tn measurements. At last, the size of the inclusion can also play a role since the lifetime of the superheated state is inversely correlated to the volume of the inclusion space (see below Eq. (6)). However, the expected relationship is not systematically met, according to our measurements (see the "interpretation" section and Fig. 8b).

To minimize the discrepancies related to the inter-laboratory conditions of measurement and thermal gradients in the samples, the Th-Tn difference is also plotted (Fig. 2a). The max/min $\mathrm{Th}-\mathrm{Tn}$ interval is a good indication of the superheating ability of the trapped liquid which partly depends on the local environment in the inclusion. The random presence of microcracks, crevices, sharp edges, ..., favors the trapping of minute amounts of gases and then their further growing at cooling, which strongly decreases the superheating ability of liquid. Also, the presence of dissolved nonpolar gases or of any suspended particles even of nanometric size, disturb the local liquid structure and favor the critical density fluctuations triggering bubble nucleation. Generally speaking, this corresponds to the duality between homogeneous nucleation, only related to the intrinsic cohesion of the liquid, and the heterogeneous nucleation where $E_{b}$ is lowered by local peculiarities in liquid or related to the solid walls. Finally, increasing the run temperatures at constant pressure (= decreasing the water density) leads to decreasing Th-Tn intervals, which is expected because of the decreasing size of the metastable domain (positive slope of the spinodal, Fig. 1).

The conversion of micro-thermometric data into water tension is done using the EoS currently recommended by the International Association for the Properties of Water and Steam, usually called the IAPWS-95 equation (Wagner and Pruss, 2002). The density at Th is first calculated, after which the (Tn, $\left.\rho_{\mathrm{BULK}}\right)$ pair are used to calculate the nucleation pressure $\mathrm{Pn}$, that is the tension in the liquid just before the nucleation occurred. This assumes that the IAPWS-95 equation retains its validity even extrapolated beyond its normal domain. Wagner and Pruss (2002) specifically tested the capabilities of their equation in metastable domains (superheating/supercooling) and found it to fit very well the (rare) existing data. In addition, it can be noticed that, as expected, the isochoric behavior remains continuous from high pressure to high tension (as are the isenthalpic and isentropic curves). The isochores plot tangentially to the spinodal curve as anticipated since one spinodal curve can also be defined as the envelope curve of all isochores. In others words, the calculation keeps its internal consistency over the entire metastability space. Eventually, from a molecular point of view, the percolation model of Stanley and Teixeira (1980), which is able to explain a large number of anomalous properties of water by means of a physical theory of hydrogen bonds connectivity, supports the extrapolation of EoS from stable domains to metastable regions. For instance, the supercooling ability of water is explicitly accounted for by the authors as favoring the stability of the bonds. In the same way, we could propose that the superheating favors the bonds having an ideal tetrahedral symmetry, meaning that a continuous behavior of the bonds networking from stable to superheating regions must be expected.

Three features can be specifically highlighted from the $P-T$ phase diagram (Fig. 2b). First, the linear alignment of $(T, P)$ pairs along mean isochores, also consistent with the synthesis 
conditions, demonstrates that the assumption of the isochoric cooling is globally met.

Secondly, the maximal Pn (lowest Th-Tn interval in one sample) is consistent with the tensile force deduced from the other types of experiments (Caupin and Herbert, 2006), that is around $-20,-30 \mathrm{MPa}$. Therefore, the SFI method finds a minimal work to nucleate a bubble in superheated water similar to that of the other techniques. Notwithstanding, the SFI makes it possible to explore a larger domain of metastability, with the maximal tensions much higher than the other methods. In particular, the absolute maximal tension recorded for pure water is at $\left(-117 \mathrm{MPa}, 60.5^{\circ} \mathrm{C}\right)$ (sample 31$)$, close to the Zheng et al.'s record $\left(-140 \mathrm{MPa}, 42{ }^{\circ} \mathrm{C}\right)$, and obtained with a very good reproducibility $\left(< \pm 0.5^{\circ} \mathrm{C}\right)$. Thirdly, the last very interesting conclusion inferred from the figure is that all $(P, T)$ pairs remain inside the metastable domain delineated by the kinetic spinodal curve of Kiselev and Ely (2001). In addition to the classical evidence of the exceptional cohesion of water, the present results lead to the conclusion that liquid water has a puzzling ability to reach the most tensile states theoretically predicted.

\section{2. $\mathrm{NaOH}$ solutions}

The selected solutions were dilute: $0.05,0.1$ and $0.5 \mathrm{~m} \mathrm{NaOH}$. The target was to observe whether a good quartz solvent $(\mathrm{NaOH})$ at small concentrations can enhance (or not) the superheating ability of the quasi-pure liquid water. As expected for these low salinity fluids, Th remains approximately constant, but the range in $\mathrm{Th}-\mathrm{Tn}$ decreases and is shifted towards the high tensile direction (Fig. 3).

These measurements were obtained from samples produced at very different conditions and in different apparatus. For instance, the run with samples 62 and 63 (see Fig. 3) was made in one low-temperature autoclave during long duration experiments (three months). Yet, the reduced range in Th-Tn values relative to pure water samples is similar to that of samples 31 and 32 which were annealed during 13 days only (Table 1). The same is true for samples with other densities of solutions and also for samples containing solutions of "soft" anions $\left(\mathrm{COO}_{4}^{-} \mathrm{MoO}_{4}^{-2}\right.$ and $\mathrm{WO}_{4}^{-2}$ ), mixed with 0.05 and $0.2 \mathrm{~m} \mathrm{NaOH}$ solutions (not shown).

The micro-thermometric measurements were plotted on a $P-T$ phase diagram, assuming that the dilute solutions obey the pure water EoS (Fig. 3). The $P-T$ diagram evidences the same conclusions as the histograms, showing that the inclusions belonging to the same sample display a narrower range and come nearer to the kinetic spinodal than do pure water inclusions, especially for the lowest densities.

As the surface tension is only negligibly modified for such low salinity fluids relative to pure water, the first role of the $\mathrm{NaOH}$ solutes is probably to improve the inner surface quality decreasing the number and size of singularities, that is the mean roughness. In addition, the shape of the inclusions is largely improved, with many inclusions displaying a shape close to a "negative quartz" one, more or less perfect.

These effects are consistent with the previous explanation of the Pn scattering for pure water, related to the heterogeneous nucleation occurrence.

\section{3. $\mathrm{NaCl}$ solutions}

Two salinities were chosen: 1 and $5 \mathrm{~mol} / \mathrm{kg}$. The distribution histograms (Fig. 4a) make clear first that the Th-Tn interval is practically similar to that for pure water. The second noticeable 
point is the scattering of $\mathrm{Th}-\mathrm{Tn}$ intervals which is smaller in $\mathrm{NaCl}$ solutions than in pure water SFI and is practically independent on salt concentration.

These SFI data can be compared with predictions calculated from the Anderko and Pitzer EoS (1993) for the $\mathrm{H}_{2} \mathrm{O}-\mathrm{NaCl}$ system above $300{ }^{\circ} \mathrm{C}$. This equation of state is built onto a physically sounding theory, which describes this system like a mixture of dipolar hard spheres $\left(\mathrm{H}_{2} \mathrm{O}\right.$ molecules and $\mathrm{NaCl}$ ion pairs) interacting by means of (1) repulsive, (2) dipolar and (3) short-ranged dispersion forces. Note that in the case of a mixture, the metastability domain is not bounded by the mechanical spinodal curve (Eq. (1b)), but by the diffusion spinodal one, defined by the diffusion stability criterium (Imre and Kraska, 2005):

$$
\left(\frac{\partial G}{\partial x^{2}}\right)_{T_{i} F_{y}} \geqslant 0
$$

where $G$ is the Gibbs energy and the $x_{i, j}$ 's refer to mole fractions.

As the Eos is expressed in terms of Helmholtz free energy, the diffusion stability criteria must be formulated as follows:

$$
\left(\frac{\partial \vec{f}(\hat{f}}{\partial x^{2}}\right)=\left(\frac{\partial \vec{f} A}{\partial x^{2}}\right)-\frac{\left(\frac{\partial \partial_{A}}{\partial \partial^{2}}\right)^{2}}{\left(\frac{\partial_{A}}{\partial x^{2}}\right)}
$$

with $A$ the Helmholtz free energy and $V$ the molar volume.

This criterium features the intrinsic stability of a fluid mixture with respect to any concentration fluctuations. The diffusion spinodal curve marks the extreme theoretical state, which can be reached by a fluid before its demixion into a liquid-gas association. Here are shown (Fig. 4b) the spinodal curves for $1 \mathrm{~m}$ and $5 \mathrm{~m} \mathrm{NaCl}$ from the critical curve to the limiting $300{ }^{\circ} \mathrm{C}$ temperature: it can be observed that a salinity increase shifts the spinodal curve (calculated for a given composition) towards higher temperatures in a $P-T$ diagram (for further details, see Thiéry and Mercury, 2009-b). In a $P-T$ diagram, the high-pressure part of the spinodal runs closely near the $\mathrm{H}_{2} \mathrm{O}-\mathrm{NaCl}$ critical curve before increasing markedly its slope and following a trend similar to the pure water spinodal. The stability limit location appears weakly dependent on the concentration. As a consequence, one could expect that the experimental nucleation in $\mathrm{NaCl}$ solutions should be in the same range than those observed for the pure water fluid inclusions. This expectation is enforced considering that the heterogeneous nucleation should predominate in concentrated solutions due to the presence of dissolved solutes.

Due to the impossibility to extrapolate the EoS below $300{ }^{\circ} \mathrm{C}$, the calculation of the homogenization density and pressure from experimental data was performed using the software available on the website of the Duan Research Group (http://www.geochemmodel.org/fluidinc/h2o_nacl/calc.php). For each sample, an isochoric point was calculated at positive pressure with the same temperature interval than the $\mathrm{Th}-\mathrm{Tn}$ difference (but with the 
opposite sign, of course). The isochore thus defined is extrapolated down to the nucleation temperature. This procedure is analogous, although somewhat more empirical, than the direct extrapolation of isochores calculated from a complex equation of state, as done for pure water. The calculated plots (Fig. 4c) clearly show that the saline solution is often more prone to a tensile state than is the pure water counterpart. The minimal superheating is slightly downshifted (meanly $-10 \mathrm{MPa}$ ) but always approximately at the same location for all samples. As for the maximal tensions recorded, $5 \mathrm{~m}$ solutions seem to uphold tension better than both the $1 \mathrm{~m}$ (unfortunately, there is only one sample) and pure water samples at the same temperature. Finally, we stress that the addition of a small amount of $\mathrm{NaOH}$ again leads to a clear shift to higher tension, but without the contraction of the Pn interval observed with the only-NaOH SFI.

\section{4. $\mathrm{CaCl}_{2}$ solutions}

The same 1 and $5 \mathrm{~m}$ solutions were tested, and we observed the same trends as with $\mathrm{NaCl}$ but much more marked (Fig. 5). The shift of Th with increasing concentration is much more pronounced than for $\mathrm{NaCl}$ solutions: $5 \mathrm{~m} \mathrm{NaCl} \mathrm{Th}$ is $18-19^{\circ} \mathrm{C}$ higher than pure water $\mathrm{Th}$ while $5 \mathrm{~m} \mathrm{CaCl}_{2} \mathrm{Th}$ is shifted by almost $50^{\circ} \mathrm{C}$.

As for the Th-Tn values (Fig. 5), the pure water average value is $25 \pm 5{ }^{\circ} \mathrm{C}$ with rare values around $40{ }^{\circ} \mathrm{C}$, while the $1 \mathrm{~m} \mathrm{CaCl}_{2}$ inclusions demonstrate typical $\mathrm{Th}-\mathrm{Tn}$ value at $48^{\circ} \mathrm{C}$. The $5 \mathrm{~m} \mathrm{CaCl}_{2}$ distribution histograms (Fig. 5) are less systematic with two clear maxima: Th-Tn in the $70-80{ }^{\circ} \mathrm{C}$ interval, consistent with a large shift with the concentration, but the second (and biggest maximum) is in the $20-30{ }^{\circ} \mathrm{C}$ interval, identical to what was observed with the pure water sample 15 . It has to be noted that the Th-Tn low values were all measured in sample 17, which had been synthetized along with sample 15 at $650{ }^{\circ} \mathrm{C}$, even if this is not at all an explanation. The reasons for such a double maximum are not clear yet and may relate to pre- or post-run salt distribution inside capsules as $\mathrm{CaCl}_{2}$ can form 2-, 4- and 6-hydrates, and some metastables hydrates might exist. But the key observation is that a large number of these inclusions display $\mathrm{Th}-\mathrm{Tn}$ around $75^{\circ} \mathrm{C}$, meaning that they nucleate vapor phase at very large tensions. Eventually, the difference between Th and the higher Tn is also increasing here (Fig. 5 upper), demonstrating that the corresponding nucleation barrier $E_{b}$ should increase.

The calculation of the homogenization properties was less straightforward than for $\mathrm{NaCl}$, yet based on the software available at the Duan Research Group. For Th lower than $250{ }^{\circ} \mathrm{C}$, the internet soft (http://www.geochem-model.org/models/h2o_cacl2/index.htm, details in Mao and Duan, 2008) was used with the same procedure as that for $\mathrm{NaCl}$, except for one aspect: the isochore extrapolated to convert (Tn, $\left.\rho_{\mathrm{BULK}}\right)$ into pressure coordinates was a mean isochore for each sample. For Th greater than $250{ }^{\circ} \mathrm{C}$, the same procedure was used with the h2o_cac12 application (based on the scientific frame exposed in Duan et al., 2006), which can be downloaded from the Geochimica website (supplementary data of Duan et al., 2006: doi:10.1016/j.gca.2006.05.007). Finally, the location of the spinodal curve was assessed by displacing the pure water spinodal (keeping constant its exact shape) to fit the known critical point of $\mathrm{CaCl}_{2}$ (here up to $2 \mathrm{~m}$ after Shibue, 2003).

The corresponding phase diagram (Fig. 5 lower) clearly shows that a $\mathrm{CaCl}_{2}$ solution is more apt to tensile state than are either the pure water or the $\mathrm{NaCl}$ counterparts, especially at high salinity. There is a clear relationship between the concentration of one $\mathrm{CaCl}_{2}$ solution and its superheating ability. The minimal Pn values are very often at higher tension than they are for $\mathrm{NaCl}$ (one exception in fact: the sample 17). Meanwhile, the maximal Pn values are often 
located close to the most negative pressure ever recorded $\left(-140 \mathrm{MPa}, 42{ }^{\circ} \mathrm{C}\right.$; Zheng et al., 1991). One inclusion of the sample 6 was measured nucleating at $-146 \mathrm{MPa}$ and $100.6{ }^{\circ} \mathrm{C}$, a little more negative than the Zheng et al.'s record which was obtained with pure water in quartz.

\subsection{CsCl solutions}

The $\mathrm{CsCl}$ solution was also studied at two salinities, 1 and $5 \mathrm{~m}$. The histogram distributions (Fig. 6 upper) show the highest $\mathrm{Th}-\mathrm{Tn}$ recorded in the present study. Especially noticeable the sample 38 which contains some inclusions which did not nucleate down to $0{ }^{\circ} \mathrm{C}$, meaning that the liquid inside was in the doubly metastable (superheated-supercooled) region. Vapor bubbles sometimes appeared after successive freezing-melting sequences. One inclusion kept at $0{ }^{\circ} \mathrm{C}$ nucleated vapor only after $125 \mathrm{~min}$, despite the inclusion was at $135{ }^{\circ} \mathrm{C}$ below its $\mathrm{Th}$.

Apart from this peculiar sample, the others samples behave as alkali ones exploring high tensions and nucleating along large intervals. This behavior could be expected as quartz solubility in $\mathrm{CsCl}$ solution is much higher than in any other salt solution (except alkaline one), up to salting-in effect (Fig. 7 and Shmulovich et al., 2006).

There is no EoS available to date so that it is not possible to convert the micro-thermometric measurements into the pressure counterpart with a reasonable confidence. Roughly estimates of Pn can still be made by drawing a straight line between the $P-T$ conditions of synthesis (as measured in the IHPV with the large errors possible, see above) and the Th- $\mathrm{Ph}$ pairs, $\mathrm{Ph}$ being calculated assuming that $\mathrm{CsCl} L V$ curve obeys the Zhang\&Frantz relationships (Zhang and Frantz, 1987). Such straight isochores can be then extrapolated down to Tn. The corresponding calculated $P-T$ diagram is displayed (Fig. 6 lower) for comparison purposes with the others $P-T$ diagrams. There is the exceptional sample 38 , with a $-260 \mathrm{MPa}$ maximal tension. With the other 7 samples, $\mathrm{CsCl}$ solutions demonstrated a very good ability to sustain tension, being in the same intervals as the $\mathrm{CaCl}_{2}$ samples and so down to the $-140 \mathrm{MPa}$ extreme value.

\section{Interpretation}

Two types of effects may explain the scatter of results. First, the solubility of quartz in the different types of trapped liquids at the synthesis conditions strongly varies. As was experimentally demonstrated (Shmulovich et al., 2006), the solubility change with salinity is strongly cation-dependent (Fig. 7). In the range of our hydrothermal syntheses, $\mathrm{CsCl}$ acts as $\mathrm{NaOH}$ does, increasing the solubility of quartz, so that it seems reasonable to expect a better quality of the inner quartz wall surfaces. However, $\mathrm{NaCl}$ and $\mathrm{CaCl}_{2}$ solutions cause the quartz solubility to decrease with respect to pure water, and should play in the same superheating fields with a bonus for the $\mathrm{NaCl}$ (more dissolving) solutions. This is not observed which indicates that a second (at least) process is acting, the surface tension effect connected to the work of nucleation.

In general, the liquid-vapor surface tension of solutions increases with respect to that of the pure water solvent, and it does so as much as the salinity increases (Weissenborn and Pugh, 1996). Practically speaking, that means that the energetic cost of creating vapor-liquid surface increases and so the nucleation barrier. Interestingly, the surface tension of $\mathrm{CaCl}_{2}$ solution increases with the electrolyte concentration by twice as much as $\mathrm{NaCl}$ does (Weissenborn and Pugh, 1996). These authors explain such a difference by the structure-maker profile of $\mathrm{Ca}^{2+}$ 
(strongly negative standard molar entropy of hydration) while $\mathrm{Na}^{+}$is a slight structure-breaker cation (weakly positive entropy of hydration). In any case, this effect can be reasonably connected with the superheating behavior of these two solutions: the higher the surface tension, the higher the superheating. Following the same line of reasoning, the $\mathrm{CsCl}$ has the smallest increase of the liquid-vapor surface tension with respect to pure water, a little lower than that of $\mathrm{NaCl}$ solution.

The two contributions must be clearly distinguished and ranked. The most important role is played by the quality of the solid-solution interface, as is demonstrated by both the $\mathrm{NaOH}$ and the $\mathrm{CsCl}$ solutions. This conclusion was reached by Skripov (1974) who showed that vapor nucleation arises along the solid-liquid boundary.

However, two observations show that other effects may be acting in some cases. The first shows a relationship between the ( $\mathrm{Th}-\mathrm{Tn}$ ) range and the inclusion size, for round inclusions whatever the composition of the trapped liquids (Fig. 8a). Obviously, the surface tension and the quartz solvent effects are here dominated by another effect connected to the size and the shape of the inclusions. Interestingly, the volume-superheating relationship follows the classic expectation of an increasing metastability range with decreasing volume of the superheated liquid (see Eq. (6) below). Secondly, at (approximately) constant size, Fig. 8b shows that the relationship between size and Tn can also been the reverse of what is expected. This demonstrates that the mechanisms enabling the superheating are numerous and strongly dependent on local (microscopic) situations.

The saline solutions have a better capability to get nearer to their thermodynamic limit than the pure water does. The exact location of this limit can obviously be questioned, but the key point is that the solutions generally sustain the metastable state better than pure water. This can be referred above all to the surface tension effect which increases the energy barrier, since the dilute $\mathrm{NaOH}$ solutions, though certainly having the best inner walls quality, are still farther from the thermodynamic limit than are the other solutions.

\section{Discussion}

Pure water and aqueous solutions have a strong ability to undergo tensile stress. The thermodynamic properties of superheated solutions make them to behave differently with respect to solids and gases solubilities (e.g. [Zilberbrand, 1999], [Mercury et al., 2003], [Mercury et al., 2004] and [Lassin et al., 2005]), which in turn should affect the resulting mineralogical assemblages.

However superheating is a transitory phenomenon, the lifetime of which depends on the nucleation barrier and also on the volume of the superheated liquid. According to the Classic Nucleation Theory, the nucleation rate of a vapor bubble follows an Arrhenius law (e.g. Debenedetti, 1996):

$$
J=J^{\circ} \cdot \exp \left(-E_{b} / k T\right)
$$

with $J$ the number of nuclei per $\mathrm{m}^{3}$ and per second, $J^{\circ}$ a kinetic pre-factor, $E_{b}$ the nucleation barrier related to the cost of surface creation. The nucleation probability $P$ in a volume $V$ and during a time $\tau$ is: 


$$
P=\exp (-J V \tau)
$$

Nucleation is assumed to occur when $P=1 / 2$. Then, the median value of the superheating lifetime $\tau_{m}$ writes:

$$
\tau_{m}=\ln (2) / J V
$$

Then, the time necessary for forming a triggering bubble nucleus depends on the space available to the fluid. As a rule of thumb, if one second is sufficient to create one critical nucleus in a volume of 11 , more than 11 days are required in a volume of $1 \mathrm{~mm}^{3}$, and statistically, almost 32,000 years are necessary in a volume of $1000 \mu \mathrm{m}^{3}$, which is a typical size for interstitial pores in sedimentary rocks. This calculation is made at constant $J$, that is at a given value of $E_{b}$, depending on the superheating "intensity" (Th-Tn here) and on the occurrence of heterogeneous nucleation. However, at constant physico-chemical conditions, nucleation is an event that becomes rare in a small container.

Therefore, as long as the water solvent sustains its superheating state, it has modified thermodynamic properties which can be calculated by extrapolating the EoS. These modified thermodynamic properties should change the solid-solution interactions behavior. This assertion must be proved, developed, and applied to actual geological situations, but one additional figure illustrates (if not demonstrate) the role of such a variation (Fig. 9). (Hemley et al., 1986) and (Hemley et al., 1992) showed that the solubility of five sulfides increases with decreasing pressure at different temperatures between $300(50$ and $100 \mathrm{MPa})$ or $400{ }^{\circ} \mathrm{C}$ $(200 \mathrm{MPa})$ and $500{ }^{\circ} \mathrm{C}$. We have extrapolated the isobaric solubility trends down to $200{ }^{\circ} \mathrm{C}$ and plotted as well the $1 \mathrm{~m} \mathrm{NaCl}$ spinodal at this temperature (plot itself obtained by smooth extrapolation of the Anderko-Pitzer spinodal, stopped at $300{ }^{\circ} \mathrm{C}$, see above) (Fig. 9). This example shows that superheated solutions have strongly modified solubilities, which could open new avenues to exploit the metastable solution occurrences either to renew the modeling of some geochemical processes (ore deposits) or for experimental purposes like in green chemistry (e.g. [Chienthavorn and Su-in, 2006] and [Smith, 2006]).

\section{Conclusion}

It has been experimentally demonstrated that the superheating ranges of liquid water and aqueous solutions are very large, down to the extreme tensile state defined by the kinetic spinodal curve (Kiselev and Ely, 2001). The nucleation threshold plots in the same range as recorded by any superheating protocol. But the present work, after others, exemplifies that the range of accessible superheating is far more extended with SFI than with any other method. The most negative pressure ever recorded has been measured in one $5 \mathrm{~m} \mathrm{CaCl}_{2}$ inclusion (in quartz): $-146 \mathrm{MPa}$ at $100{ }^{\circ} \mathrm{C}$. The previous record was established with a pure water inclusion (also in quartz) at $-140 \mathrm{MPa}$ and $42{ }^{\circ} \mathrm{C}$ (Zheng et al., 1991). This conclusion does not consider the $\mathrm{CsCl}$ solutions experiments since the way to translate the $\mathrm{Th}-\mathrm{Tn}$ data into $\mathrm{Pn}$ is, by far, too rough to enable a rigorous comparison with the other datasets. Eventually, two parameters seem to control the range of possible tensions as well as the value of the maximum tension: (1) the solution-vapor surface tension, which increases the nucleation barrier; (2) the quartz solubility in the targeted solution at the SFI synthesis conditions, which improves the surface quality of the inner solid walls and so allows to pass from an heterogeneous- to an homogeneous-dominated nucleation behavior. However, other parameters are clearly 
controlling the superheated liquid-vapor phase transition, probably at the micrometric scale, but whose mechanism(s) of influence are not clear yet.

In terms of the applicability to natural contexts, and as noted above, it is possible to expect that the superheating geochemistry plays a role in the area of the ore deposits genesis. This is supported by evidence obtained through the extrapolation of some experimental works (Hemley et al., 1992 and Fig. 9). Generally speaking, the superheating state of one solution may have a geochemical influence whenever its special properties have time to modify the rock-solutions equilibria, then changing the mass balance in one system. The soils systems in semi-arid and arid zones are the most probable target for this role since their soil solutions can be brought at high superheating state by the capillarity effect (e.g. Pettenati et al., 2008).

The second applicability for the superheating in a natural context is the potential role on the explosivity of pure water (Thiéry and Mercury, 2009-a) and aqueous solutions (Thiéry and Mercury, 2009-b). This relates to the influence of the kinetics of the $L V$ phase transition which acquires violent features when brought to the conditions of the spinodal decomposition.

It is interesting to note that these geochemical and explosive effects can act together. When the physical transition $(L \rightarrow L+V)$ takes place, there is a simultaneous change of the thermodynamic conditions of the solid-solution systems, so that the place of the $L V$ transition is the place where the geochemical consequences occur. Superheating geochemistry (solubility of gases and solids) is in fact associated with superheating geomechanics (water as an explosive, dihedral angle and the hydraulic continuity of crustal fluids). This conclusion is not new: Adushkin et al. (2004) argued that the cavitation bubbles which may develop in hydrothermal fluids due to a Venturi effect (hydrodynamic cavitation: superheated liquid-tovapor transition) are responsible for the formation of micro-spherules of ore minerals.

Finally, for the sake of comprehensiveness, another geological application of metastable states can be proposed for crustal fluids. Metastable liquids are most stable as pocketed discontinuous volumes but are sensitive to waves propagation: it is well-known that a very slight shock wave is sufficient to make a superheated liquid to explode. By this way, if some crustal fluids disseminated in finely porous rocks become superheated, we suggest that the propagation of seismic waves in the deep crust might trigger the explosion of such metastable solutions, the emptied channels becoming a reflector for next seismic wave trains.

\section{Acknowledgments}

This work has received financial support from the French Agency for Research (Agence Nationale de la Recherche), grant SURCHAUF-JC05-48942 and from Russian Fund of Basic Investigations, Grant 06-05-64460. The authors warmly thank Bruce Yardley who patronized the connection between many of those who formed, soon after, the SURCHAUF scientific team. Great acknowledgments are due to Colin Graham, who welcome K.S. at the School of Geosciences in Edinburgh to carry out the hydrothermal synthesis. The careful reviews of Prof. Bodnar (who also took time to annotate the manuscript) and one anonymous reviewer as well as the editor review of Prof. Duan, considerably improved the scientific quality and the English spelling of the manuscript. A final reading by Dr. Bruno Scaillet is also acknowledged. 


\section{References}

Adushkin et al., 2004 V.V. Adushkin, S.N. Andreev and S.I. Popel, Cavitation mechanism of formation of nano- and microsize particles of minerals in ore deposits, Geol. Ore Deposits 46 (5) (2004), pp. 313-320.

Alvarenga et al., 1993 A.D. Alvarenga, M. Grimsditch and R.J. Bodnar, Elastic properties of water under negative pressures, J. Chem. Phys. 98 (11) (1993), pp. 8392-8396.

Anderko and Pitzer, 1993 A. Anderko and K.S. Pitzer, Equation-of-state representation of phase equilibria and volumetric properties of the system $\mathrm{NaCl}-\mathrm{H}_{2} \mathrm{O}$ above $573 \mathrm{~K}$, Geochim. Cosmochim. Acta 57 (8) (1993), pp. 1657-1680.

Apfel, 1972 R.E. Apfel, The tensile strength of liquids, Sci. Am. 227 (6) (1972), pp. 58-71.

Bakker and Jansen, 1994 R.J. Bakker and J.B.H. Jansen, A mechanism for preferential $\mathrm{H}_{2} \mathrm{O}$ leakage from fluid inclusions in quartz, based on TEM observations, Contrib. Mineral. Petrol. 116 (12-2) (1994), pp. 7-20.

Bakker and Jansen, 1991 R.J. Bakker and J.B.H. Jansen, Experimental post-entrapment water loss from synthetic $\mathrm{CO}_{2}-\mathrm{H}_{2} \mathrm{O}$ inclusions in natural quartz, Geochim. Cosmochim. Acta 55 (8) (1991), pp. 2215-2230.

Bodnar et al., 1989 R.J. Bodnar, P.R. Binns and D.L. Hall, Synthetic fluid inclusions. VI. Quantitative evaluation of the decrepitation behavior of fluid inclusions in quartz at one atmosphere confining pressure, J. Metam. Geol. 7 (1989), pp. 229-242.

Bodnar and Sterner, 1985 R.J. Bodnar and S.M. Sterner, Synthetic fluid inclusions in natural quartz. II. Application to PVT studies, Geochim. Cosmochim. Acta 49 (9) (1985), pp. 18551859.

Briggs, 1950 L.J. Briggs, Limiting negative pressure of water, J. Appl. Phys. 21 (1950), pp. $721-722$.

Briggs, 1955 L.J. Briggs, Maximum superheating of water as a measure of negative pressure, J. Appl. Phys. 26 (8) (1955), pp. 1001-1003.

Caupin and Herbert, 2006 F. Caupin and E. Herbert, Cavitation in water: a review, C.R. Phys. 6 (2006), pp. 1000-1017.

Chienthavorn and Su-in, 2006 O. Chienthavorn and P. Su-in, Modified superheated water extraction of pesticides from spiked sediment and soil, Anal. Bioanal. Chem. 385 (2006), pp. 83-89.

Dayton, 1739 J. Dayton, An experience to prove, that water, when agitated by fire, is infinitely more elastic than air in the same circumstances, Phil. Trans. 41 (1) (1739), pp. 162166.

Debenedetti, 1996 P.G. Debenedetti, Metastable Liquids. Concepts and Principles, Princeton University Press, Princeton, NJ (1996). 
Duan et al., 2006 Z.H. Duan, N. Moller and J.H. Weare, A high temperature equation of state for the $\mathrm{H}_{2} \mathrm{O}-\mathrm{CaCl}_{2}$ and $\mathrm{H}_{2} \mathrm{O}-\mathrm{MgCl}_{2}$ systems, Geochim. Cosmochim. Acta 70 (2006), pp. 3765-3777.

Goldstein and Reynolds, 1994 R.H. Goldstein and T.J. Reynolds, Systematics of fluid inclusions in diagenetic minerals, SEPM Short Course Notes 31 (1994), pp. 189-198.

Green et al., 1990 J.L. Green, D.J. Durben, G.H. Wolf and C.A. Angell, Water and solutions at negative pressure: Raman spectroscopic study to -80 Megapascals, Science 249 (1990), pp. 649-652.

Hayward, 1971 A.T.J. Hayward, Negative pressure in liquids: can it be harnessed to serve man?, Am. Sci. 59 (1971), pp. 434-443.

Hemley et al., 1986 J.J. Hemley, G.L. Cygan and W.M. d'Angelo, Effects of pressure on ore mineral solubilities under hydrothermal conditions, Geology 14 (1986), pp. 377-379.

Hemley et al., 1992 J.J. Hemley, G.L. Cygan, J.B. Fein, G.R. Robinson and W.M. d'Angelo, Hydrothermal ore-forming processes in the light of studies in rock-buffered systems: I. Ironcopper-zinc-lead sulphide solubility relations, Econom. Geol. 87 (1) (1992), pp. 1-22.

Imre and Kraska, 2005 A. Imre and T. Kraska, Stability limits in binary fluid mixtures, $J$. Chem. Phys. 122 (2005), pp. 1-8.

Imre et al., 1998 A. Imre, K. Martinas and L.P.N. Rebelo, Thermodynamics of negative pressures in liquids, J. Non-Equilib. Thermodyn. 23 (4) (1998), pp. 351-375.

Imre and Van Hook, 1998 A. Imre and W.A. Van Hook, Liquid-liquid equilibria in polymer solutions at negative pressure, Chem. Soc. Rev. 27 (1998), pp. 117-123.

Imre et al., 2008 A. Imre, A. Drodz-Rzoska, A. Horvath, T. Kraska and S. Rzoska, Solidfluid phase transitions under extreme pressures including negative ones, J. Non-Crystalline Solids 354 (2008), pp. 4157-4162.

Kell, 1983 G.S. Kell, Early observations of negative pressures in liquids, Am. J. Phys. 51 (11) (1983), pp. 1038-1041.

Kiselev and Ely, 2001 S.B. Kiselev and J.F. Ely, Curvature effect on the physical boundary of metastable states in liquids, Physica A 299 (2001), pp. 357-370.

Lassin et al., 2005 A. Lassin, M. Azaroual and L. Mercury, Geochemistry of unsaturated soil systems: aqueous speciation and solubility of minerals and gases in capillary solutions, Geochim. Cosmochim. Acta 69 (22) (2005), pp. 5187-5201.

Mao and Duan, 2008 S.D. Mao and Z.H. Duan, The PVTX properties of binary aqueous chloride solutions up to $T=573 \mathrm{~K}$ and $100 \mathrm{MPa}$, J. Chem. Therm. 40 (7) (2008), pp. 10461063.

Mercury and Tardy, 1997a L. Mercury and Y. Tardy, Negative pressure and thermodynamic properties of capillary water, C.R. Acad. Sci. Paris 324 (11) (1997), pp. 863-873. 
Mercury and Tardy, 1997b L. Mercury and Y. Tardy, Physicochemical features of water in capillaries and fog water droplets, C.R. Acad. Sci. Paris 325 (12) (1997), pp. 947-954.

Mercury and Tardy, 2001 L. Mercury and Y. Tardy, Negative pressure of stretched liquid water. Geochemistry of soil capillaries, Geochim. Cosmochim. Acta 65 (20) (2001), pp. 33913408.

Mercury et al., 2003 L. Mercury, M. Azaroual, H. Zeyen and Y. Tardy, Thermodynamic properties of solutions in metastable systems under negative or positive pressures, Geochim. Cosmochim. Acta 67 (2003), pp. 1769-1785

Mercury et al., 2004 L. Mercury, D.L. Pinti and H. Zeyen, The effect of the negative pressure of capillary water on atmospheric noble gas solubility in ground water and palaeotemperature reconstruction, Earth Planet. Sci. Lett. 223 (2004), pp. 147-161

Pettenati et al., 2008 M. Pettenati, L. Mercury and M. Azaroual, Capillary geochemistry in non-saturated zone of soils. Water content and geochemical signatures, Appl. Geochem. 23 (2008), pp. 3799-3818.

Ramboz and Danis, 1990 C. Ramboz and M. Danis, Superheating in the Red Sea? The heatmass balance of the Atlantis II Deep revisited, Earth Planet. Sci. Lett. 97 (1990), pp. 190210.

Reid, 1976 R.C. Reid, Superheated liquids, Am. Sci. 64 (1976), pp. 146-156.

Roedder, 1967 E. Roedder, Metastable superheated ice in liquid-water inclusions under high negative pressure, Science 155 (1967), pp. 1413-1417.

Shibue, 2003 Y. Shibue, Vapour pressures of aqueous $\mathrm{NaCl}$ and $\mathrm{CaCl}_{2}$ solutions at elevated temperatures, Fluid Phase Equil. 213 (2003), pp. 39-51.

Shmulovich and Graham, 2004 K.I. Shmulovich and C.M. Graham, An experimental study of phase equilibria in the systems $\mathrm{H}_{2} \mathrm{O}-\mathrm{CO}_{2}-\mathrm{CaCl}_{2}$ and $\mathrm{H}_{2} \mathrm{O}-\mathrm{CO}_{2}-\mathrm{NaCl}$ at high pressures and temperatures $\left(500-800{ }^{\circ} \mathrm{C}, 0.5-0.9 \mathrm{GPa}\right)$ : geological and geophysical applications, Contrib. Mineral. Petrol. 146 (2004), pp. 450-462.

Shmulovich et al., 2006 K.I. Shmulovich, B.W.D. Yardley and C.M. Graham, Solubility of quartz in crustal fluids: experiments and general equations for salt solutions and $\mathrm{H}_{2} \mathrm{O}-\mathrm{CO}_{2}$ mixtures at $400-800^{\circ} \mathrm{C}$ and $0.1-0.9 \mathrm{GPa}$, Geofluids 6 (2006), pp. 154-167.

Skripov, 1974 Skripov V. P. (1974) Metastable Liquids. J. Wiley \& Sons, New York, and Israel Program for Scientific Translations, Jerusalem, 272p.

Smith, 2006 R.M. Smith, Superheated water: the ultimate green solvent for separation science, Anal. Bioanal. Chem. 385 (2006), pp. 419-421.

Stanley and Teixeira, 1980 H.E. Stanley and J. Teixeira, Interpretation of the unusual behavior of $\mathrm{H}_{2} \mathrm{O}$ and $\mathrm{D}_{2} \mathrm{O}$ at low temperatures: tests of a percolation model, J. Chem. Phys. 73 (7) (1980), pp. 3404-3422. 
Steinberg et al., 1982 G.S. Steinberg, A.G. Merzhanov and A.S. Steinberg, Geyser process: its theory, modelling, and field experiment. Part 3. On metastability of water in geysers, Modern Geol. 8 (1982), pp. 75-78.

Tas et al., 2003 N.R. Tas, P. Mela, T. Kramer, J.W. Berenschot and A. van den Berg, Capillarity induced negative pressure of water plugs in nanochannels, Nano Lett. 3 (11) (2003), pp. 1537-1540.

Thiéry and Mercury, 2009-a Thiéry R. and Mercury L. (2009-a) Explosive properties of water in volcanic and hydrothermal systems. J. Geophys. Res. doi:10.1029/2008JB005742.

Thiéry and Mercury, 2009-b Thiéry R. and Mercury L. (2009-b) Explosivity conditions of aqueous solutions. J. Sol. Chem. 38(7), xxx-xxx.

Trevena, 1987 D.H. Trevena, Cavitation and Tension in Liquids, Adam Hilger, Bristol (1987).

Wagner and Pruss, 2002 W. Wagner and A. Pruss, The IAPWS formulation 1995 for the thermodynamic properties of ordinary water substance for general and scientific use, J. Phys. Chem. Ref. Data 31 (2) (2002), pp. 387-535.

Weissenborn and Pugh, 1996 P.K. Weissenborn and R.J. Pugh, Surface tension of aqueous solutions of electrolytes: relationship with ion hydration, oxygen solubility, and bubble coalescence, J. Colloid Interf. Sci. 184 (1996), pp. 550-563.

Zhang and Frantz, 1987 Y.-G. Zhang and J. Frantz, Determination of the homogenization temperatures and densities of supercritical fluids in the system $\mathrm{NaCl}-\mathrm{KCl}-\mathrm{CaCl}_{2}-\mathrm{H}_{2} \mathrm{O}$ synthetic fluid inclusions, Chem. Geol. 64 (1987), pp. 335-350.

Zheng et al., 1991 Q. Zheng, D.J. Durben, G.H. Wolf and C.A. Angell, Liquids at large negative pressures: water at the homogeneous nucleation limit, Science 254 (1991), pp. 829832.

Zilberbrand, 1997 M. Zilberbrand, A nonelectrical mechanism of ion exclusion in thin water films in finely dispersed media, J. Colloid Interf. Sci. 192 (1997), pp. 471-474.

Zilberbrand, 1999 M. Zilberbrand, On equilibrium constants for aqueous geochemical reactions in water unsaturated soils and sediments, Aquat. Geochem. 5 (1999), pp. 195-206. 


\section{Figures}

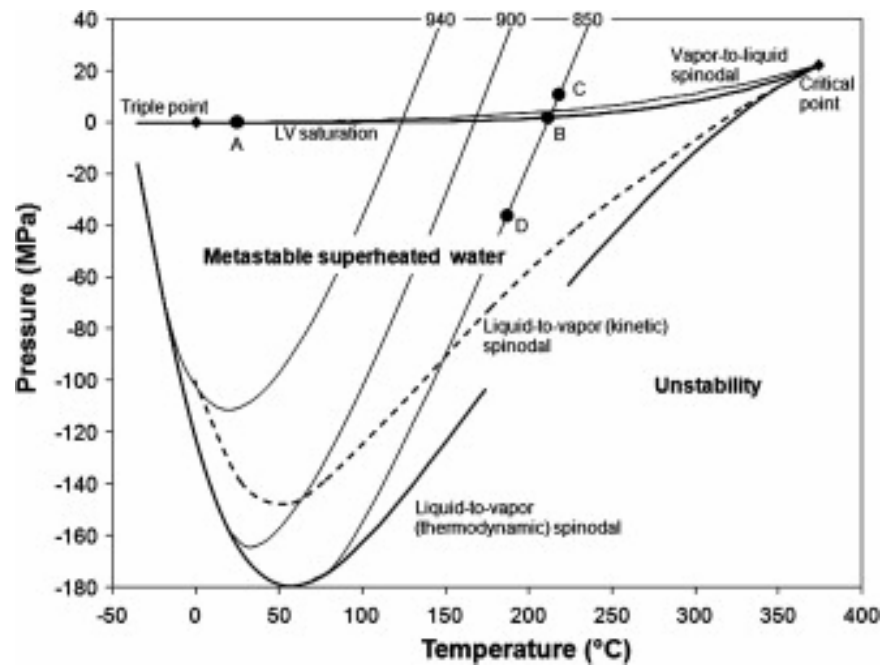

Fig. 1. Phase diagram of water in $P-T$ space, calculated with the IAPWS-P5 equation of state (Wagner and Pruss, 2002). Each isochore is labeled with the liquid density in $\mathrm{kg} \mathrm{m}^{-3}$. The kinetic spinodal is taken from Kiselev and Ely (2001). The classic micro-thermometric path is also reported from the ambient conditions (A) to the homogenization temperature (Th, B), possibly up to overheating conditions $(\mathrm{C})$, and cooled after down to the nucleation temperature (Tn, D). 
a

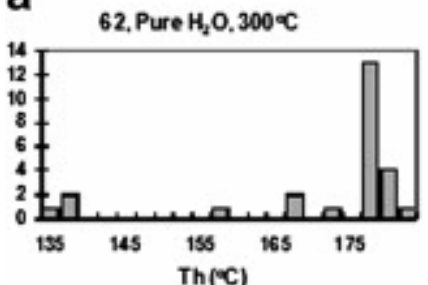

$31, \mathrm{H}_{2} \mathrm{O}, 550^{\circ} \mathrm{C}$

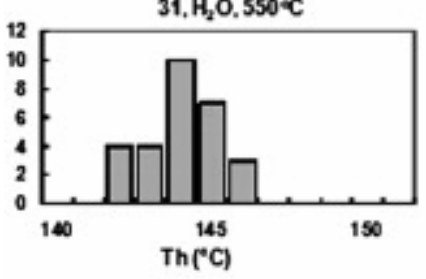

$21, \mathrm{H}_{2} \mathrm{O}, 650^{\circ} \mathrm{C}$
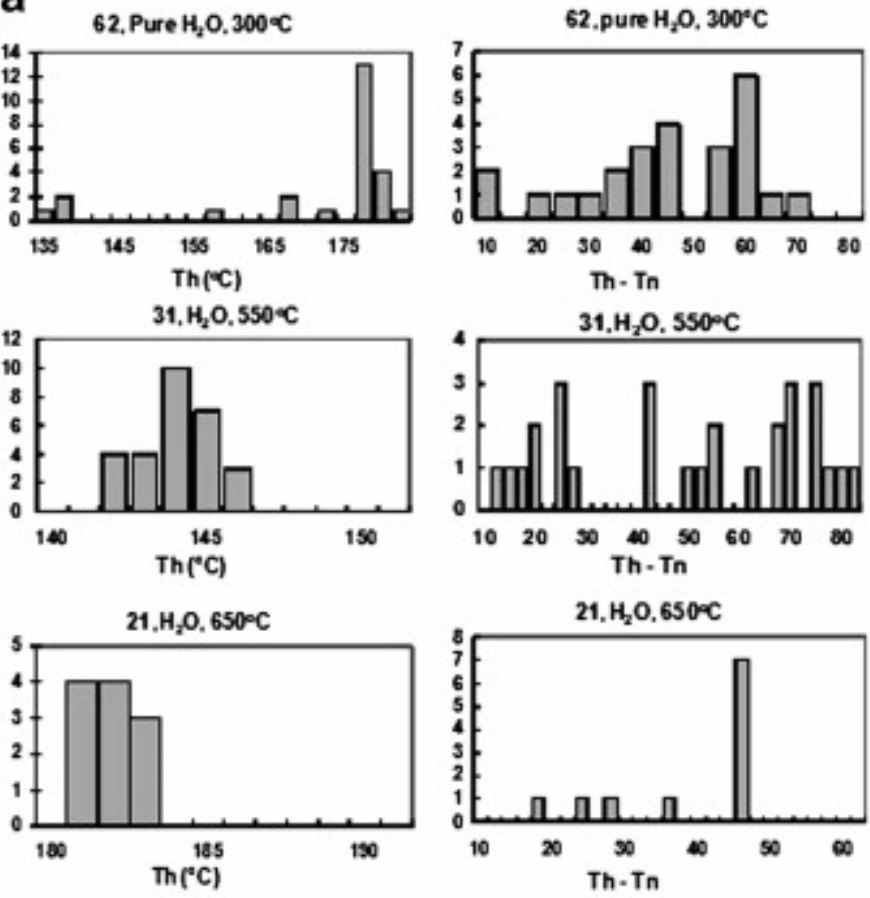

$31, \mathrm{H}_{2} \mathrm{O}, 550^{\circ} \mathrm{C}$

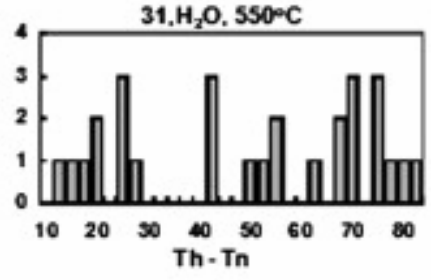

$21, \mathrm{H}_{2} \mathrm{O}, 650^{\circ} \mathrm{C}$
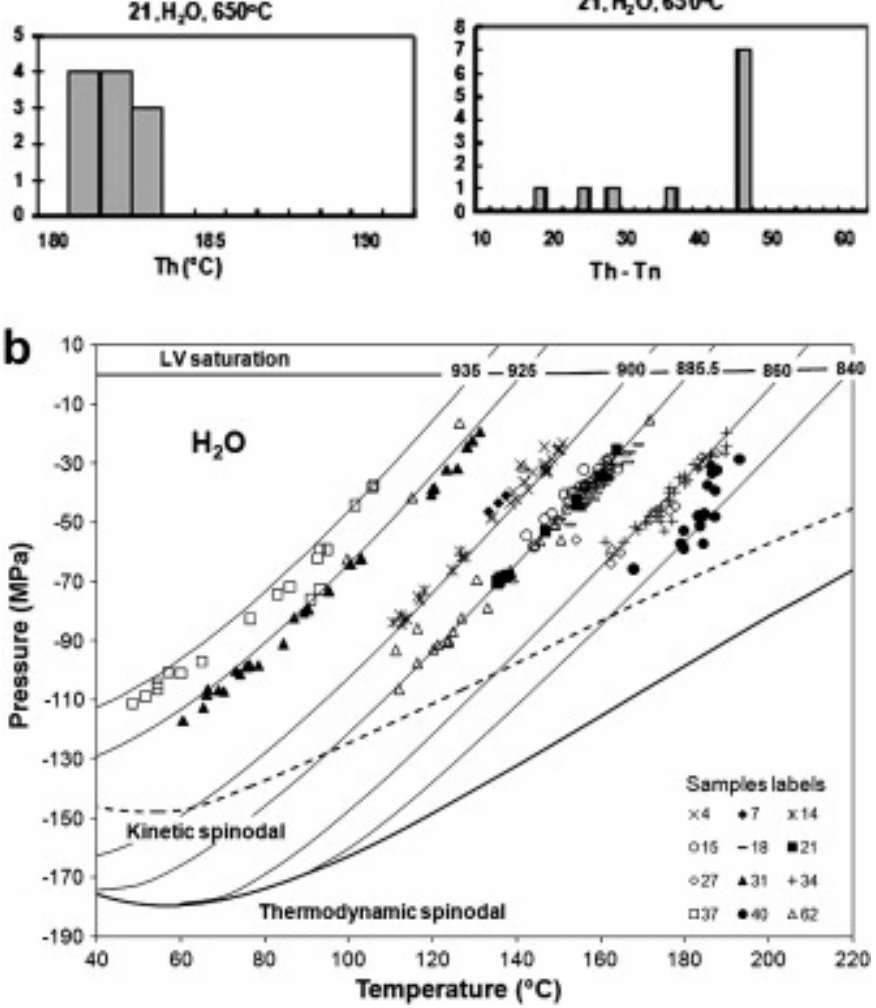

Fig. 2. (a) Micro-thermometric data of 244 pure water fluid inclusions (12 samples) trapped in quartz. (b) $P-T$ coordinates of the 244 pure water SFI, calculated using the IAPWS-95 EoS (see text). Each isochore is labeled with the liquid density in $\mathrm{kg} \mathrm{m}^{-3}$. The kinetic spinodal is from Kiselev and Ely (2001). 

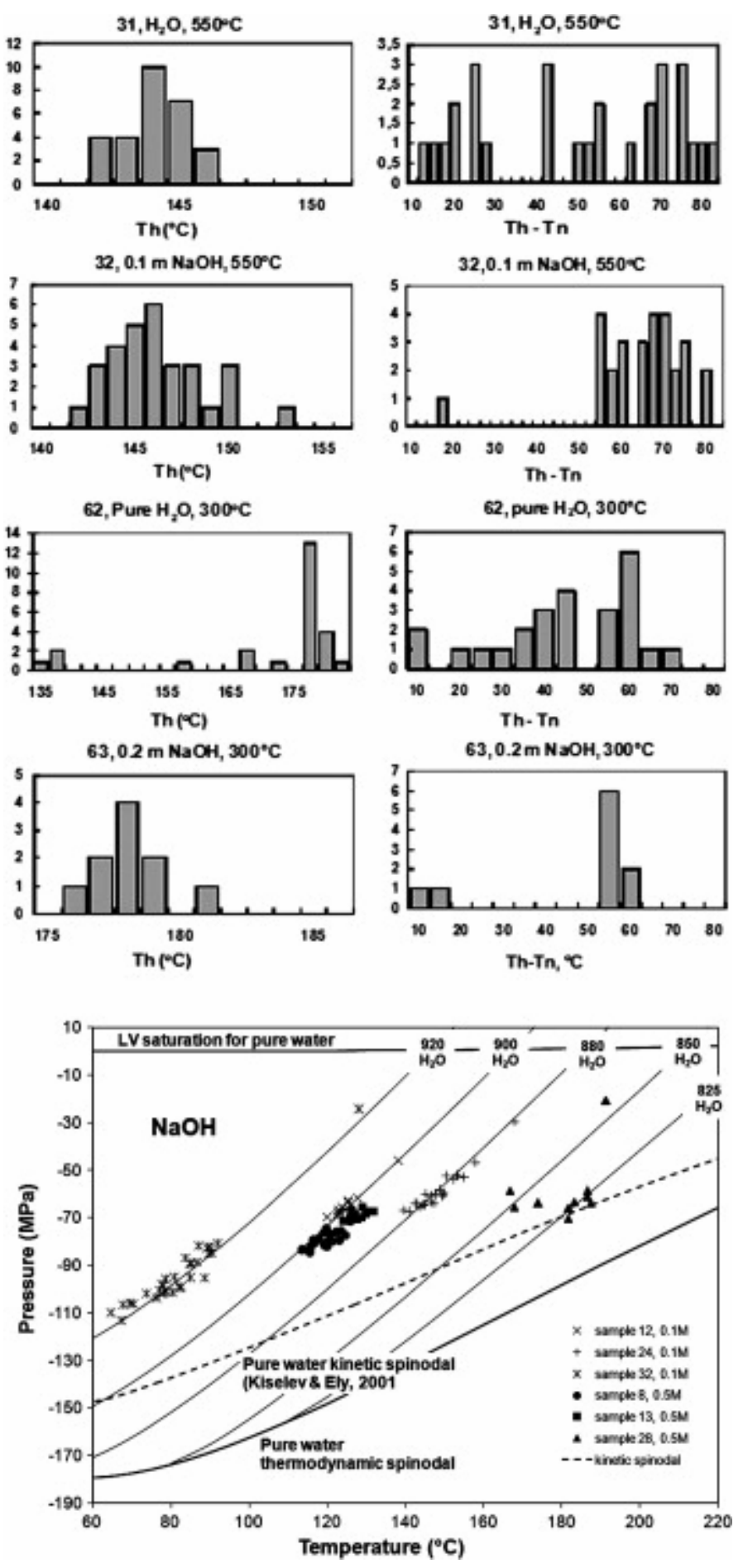

Fig. 3. Micro-thermometric data (upper) and $P-T$ coordinates (lower) of $113 \mathrm{NaOH}(0.1$ and $0.5 \mathrm{~m}$ ) fluid inclusions (6 samples) trapped in quartz. Each isochore is labeled with the liquid pure water density in $\mathrm{kg} \mathrm{m}^{-3}$. 

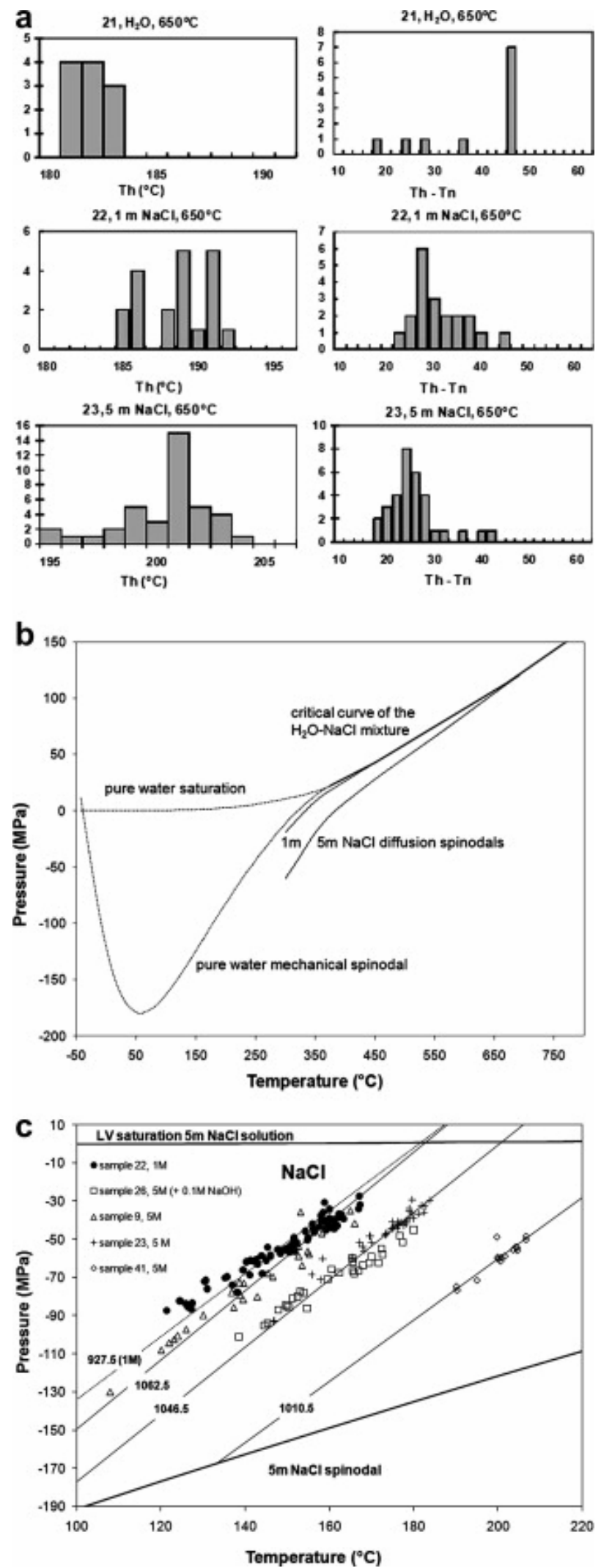

Fig. 4. (a) Micro-thermometric data recorded on $189 \mathrm{NaCl}$ (1 and $5 \mathrm{~m}$ ) fluid inclusions (5 samples) trapped in quartz. (b) $\mathrm{NaCl}$ phase diagram at different concentration including metastable superheating domain, with the Anderko and Pitzer (1993) EoS. (c) $P-T$ coordinates of the $189 \mathrm{NaCl}$ SFI. The $5 \mathrm{~m}$ spinodal is plotted by smooth extrapolation at low $T$ of the Anderko-Pitzer spinodal drawn from the critical curve to $300{ }^{\circ} \mathrm{C}$. 

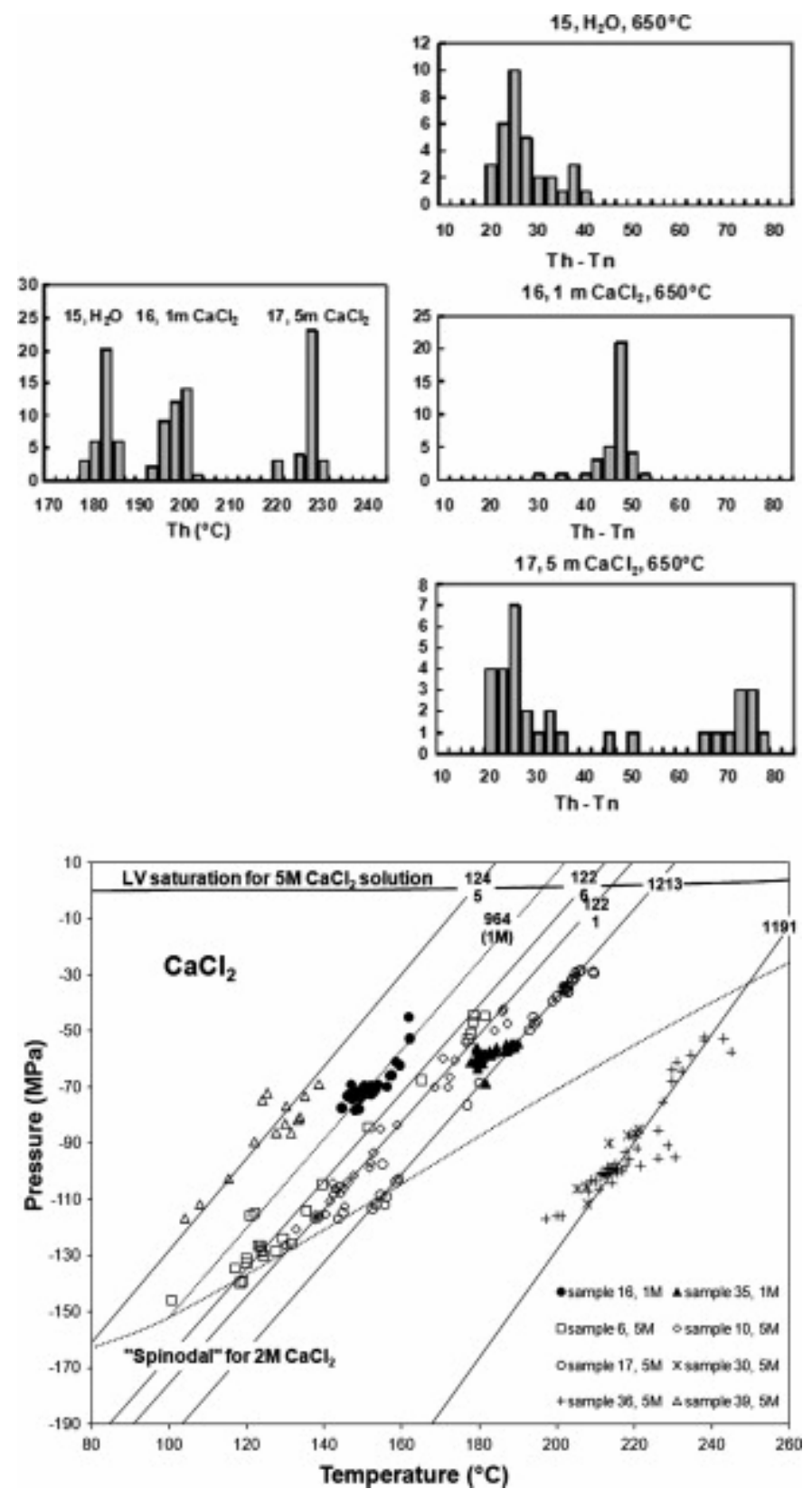

Fig. 5. Micro-thermometric data (upper) and $P-T$ coordinates (lower) of $229 \mathrm{CaCl}_{2}$ (1 and $5 \mathrm{M}$ ) fluid inclusions ( 8 samples) trapped in quartz. Each isochore is labeled with the liquid density in $\mathrm{kg} \mathrm{m}^{-3}$. 

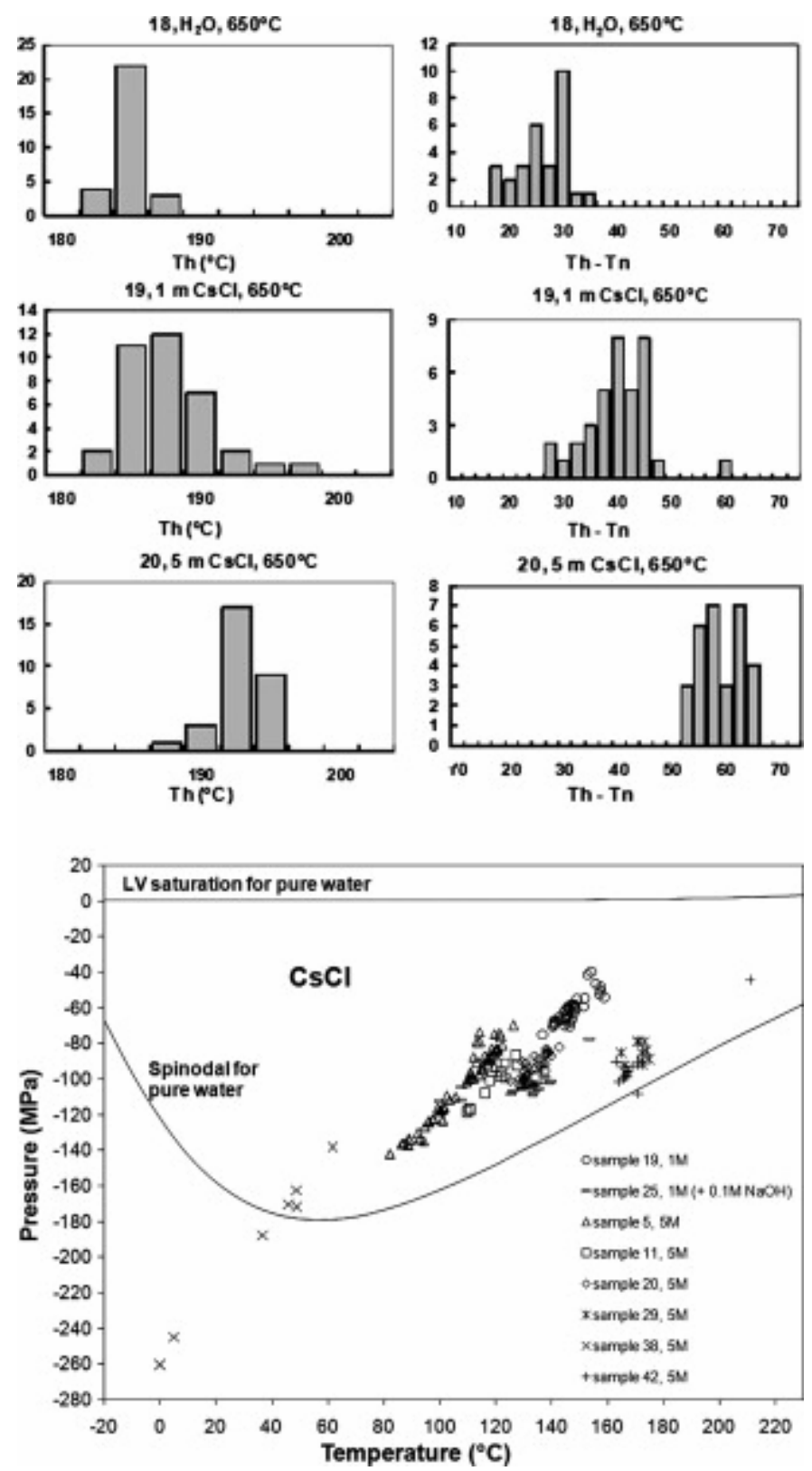

Fig. 6. Micro-thermometric data and $P-T$ coordinates (lower) of $207 \mathrm{CsCl}(1 \mathrm{~m}$ or $5 \mathrm{~m})$ fluid inclusions (8 samples) trapped in quartz. 

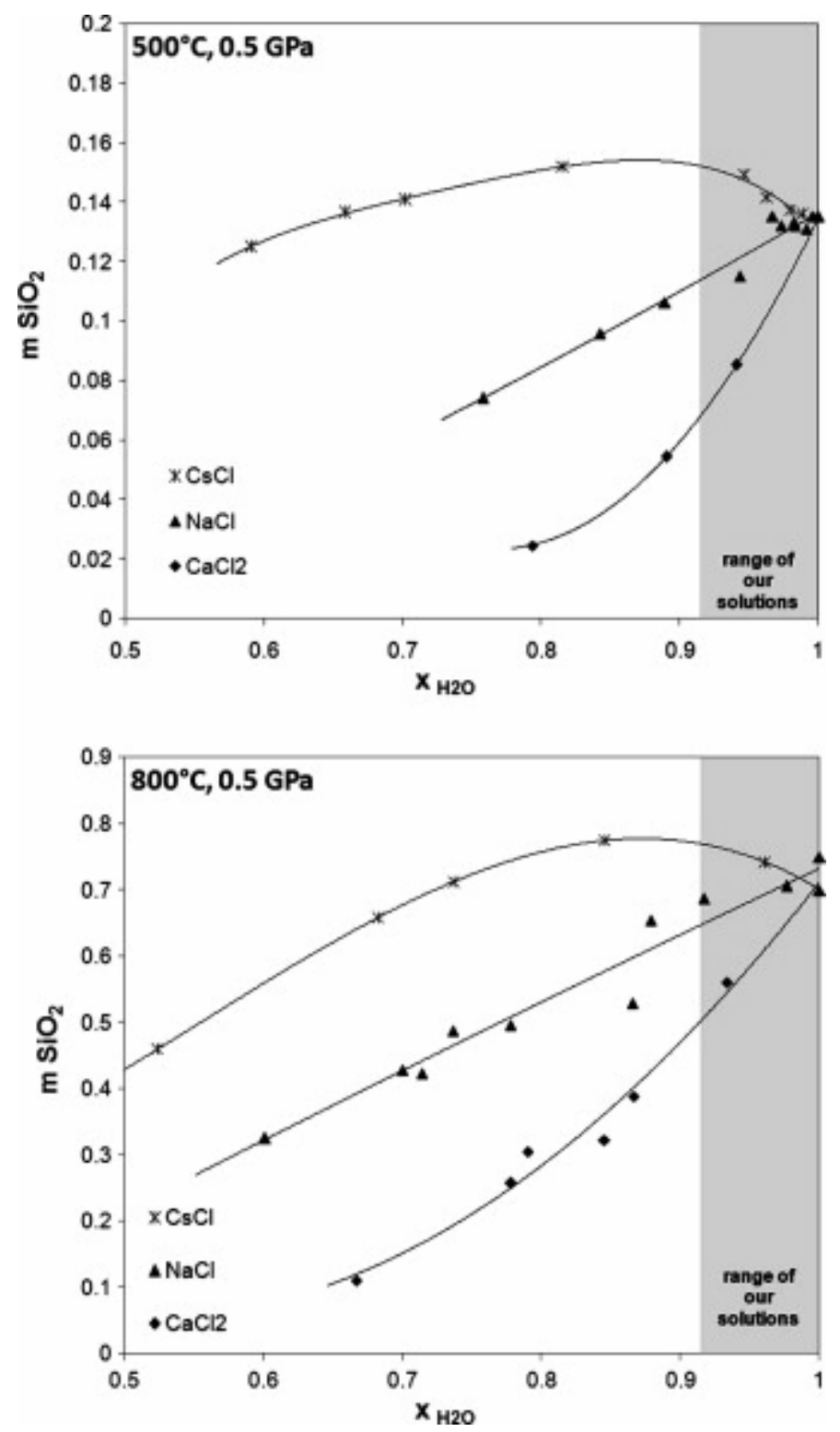

Fig. 7. Solubility of quartz in chlorides solutions at 500 and $800{ }^{\circ} \mathrm{C}$ at $0.5 \mathrm{GPa}$ (modified after Shmulovich et al., 2006). The present SFI synthesis conditions varied from 530 to $700{ }^{\circ} \mathrm{C}$ at $0.75 \mathrm{GPa}$ and $x_{\mathrm{H} 2 \mathrm{O}} \mathrm{min} .=0.917$. Curves are only guides for eyes. 

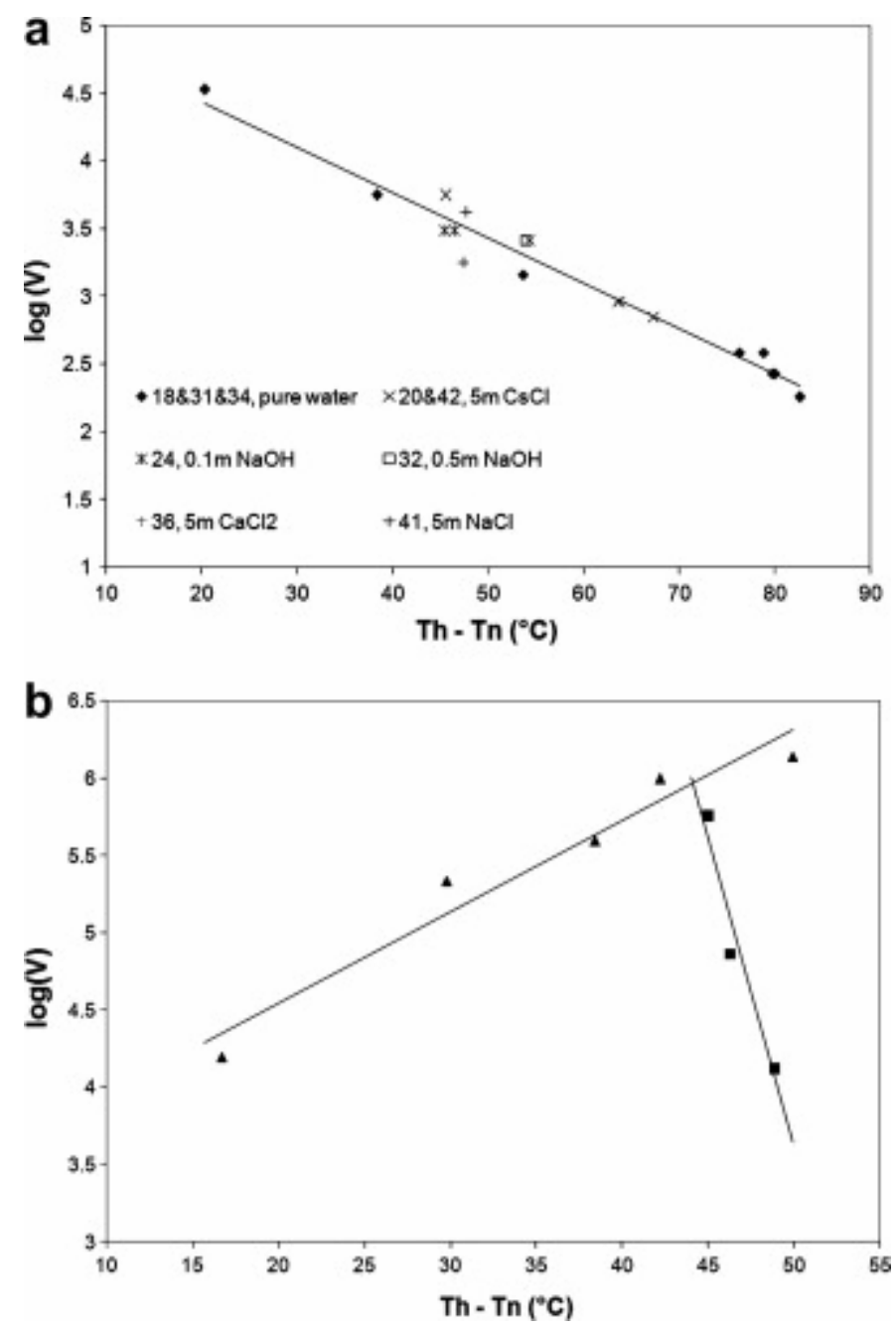

Fig. 8. (a) Increasing (Th-Tn) range as a function of decreasing volume of inclusions, whatever is the composition of the solution inside. The dataset corresponds to round inclusions, without visible faceting. (b) In the samples 13 and $28(0.5 \mathrm{~m} \mathrm{NaOH})$, relationship between (Th-Tn) and the volume of the inclusions. All the inclusions have the "negative crystal" shape but the squared markers group corresponds to inclusions much more faceted than those of the triangle markers group. The lines are only guide for eyes. 


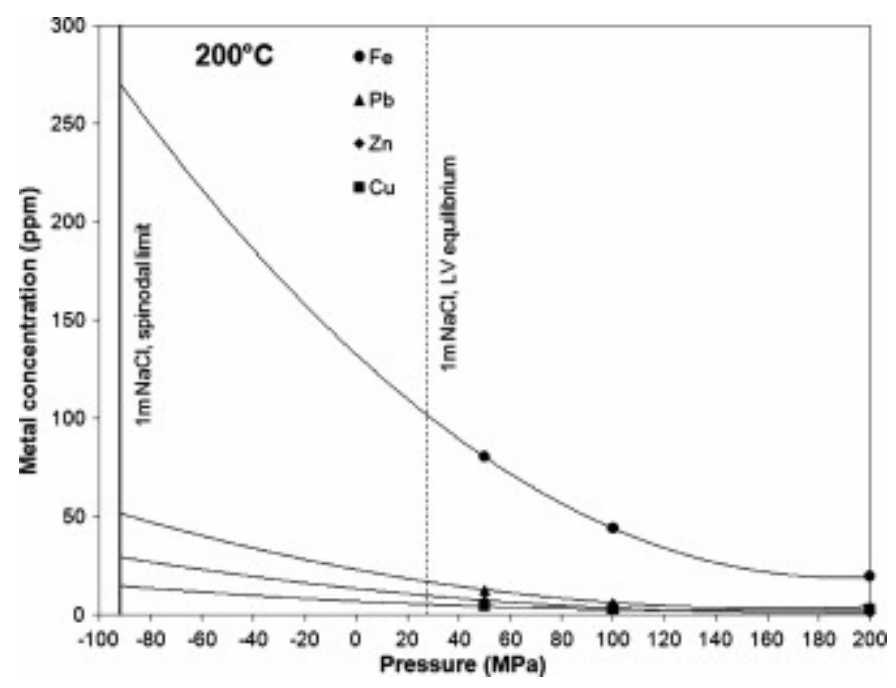

Fig. 9. Solubility of different sulfides at $200^{\circ} \mathrm{C}$ as a function of pressure, extrapolated from data obtained at higher temperatures (Hemley et al., 1992). The saturation and spinodal limits of a $1 \mathrm{~m} \mathrm{NaCl}$ solution are from the Anderko and Pitzer (1993) EoS. 
Table 1. : Synthesis conditions and micro-thermometric measurements.

\begin{tabular}{|c|c|c|c|c|c|c|c|c|c|c|}
\hline$N^{\mathrm{a}}$ & $\begin{array}{l}\text { Composition } \\
\text { studied solution }\end{array}$ & $\begin{array}{l}T \text { run } \\
\left({ }^{\circ} \mathrm{C}\right)\end{array}$ & $\begin{array}{l}t^{\mathrm{c}} \\
\text { (days) }\end{array}$ & $\begin{array}{l}\text { Th } \\
\left({ }^{\circ} \mathrm{C}\right)\end{array}$ & SD & $\begin{array}{l}\text { Tn } \\
\left({ }^{\circ} \mathrm{C}\right)\end{array}$ & SD & $\begin{array}{l}\text { Th-Tn } \\
\left({ }^{\circ} \mathrm{C}\right)\end{array}$ & SD & $n^{\mathbf{b}}$ \\
\hline 4 & $\mathrm{H}_{2} \mathrm{O}$ & 600 & 11 & 165.52 & 1.9 & 144.15 & 5.0 & 21.37 & 4.8 & 21 \\
\hline 5 & $5 \mathrm{~m} \mathrm{CsCl}$ & 600 & 11 & 168.02 & 2.6 & 107.17 & 11.8 & 60.85 & 12.0 & 67 \\
\hline 6 & $5 \mathrm{~m} \mathrm{CaCl}_{2}$ & 600 & 11 & 206.84 & 4.9 & 137.29 & 24.4 & 69.56 & 22.1 & 26 \\
\hline $7^{\mathrm{d}}$ & $\mathrm{H}_{2} \mathrm{O}$ & 600 & 10 & 162.80 & 0.3 & 135.33 & 2.1 & 27.47 & 1.8 & 3 \\
\hline $8^{\underline{d}}$ & $0.5 \mathrm{~m} \mathrm{NaOH}$ & 600 & 10 & 171.10 & 2.3 & 120.50 & 3.8 & 50.60 & 3.1 & 21 \\
\hline $9^{\underline{d}}$ & $5 \mathrm{~m} \mathrm{NaCl}$ & 600 & 10 & 182.80 & 3.9 & 141.89 & 15.2 & 40.90 & 13.7 & 28 \\
\hline $10^{\mathrm{d}}$ & $5 \mathrm{~m} \mathrm{CaCl}_{2}$ & 600 & 10 & 214.08 & 2.2 & 154.46 & 17.4 & 59.62 & 16.8 & 32 \\
\hline $11^{\mathrm{d}}$ & $5 \mathrm{~m} \mathrm{CsCl}$ & 600 & 10 & 177.77 & 1.4 & 119.38 & 6.5 & 58.39 & 6.3 & 14 \\
\hline 12 & $0.1 \mathrm{~m} \mathrm{NaOH}$ & 600 & 6.5 & 166.53 & 0.8 & 125.08 & 4.6 & 41.45 & 4.2 & 13 \\
\hline 13 & $0.5 \mathrm{~m} \mathrm{NaOH}$ & 600 & 6.5 & 172.14 & 1.7 & 127.59 & 2.3 & 44.56 & 1.1 & 14 \\
\hline 14 & $\mathrm{H}_{2} \mathrm{O}$ & 600 & 6.5 & 166.03 & 1.1 & 118.33 & 6.4 & 47.69 & 6.4 & 12 \\
\hline 15 & $\mathrm{H}_{2} \mathrm{O}$ & 650 & 8 & 180.89 & 1.9 & 154.87 & 6.2 & 26.02 & 5.7 & 35 \\
\hline 16 & $1 \mathrm{~m} \mathrm{CaCl}_{2}$ & 650 & 8 & 196.50 & 2.4 & 151.29 & 4.4 & 45.21 & 3.9 & 39 \\
\hline 17 & $5 \mathrm{~m} \mathrm{CaCl}_{2}$ & 650 & 8 & 225.53 & 2.5 & 185.88 & 22.9 & 39.65 & 21.9 & 33 \\
\hline 18 & $\mathrm{H}_{2} \mathrm{O}$ & 650 & 8 & 184.02 & 1.2 & 158.96 & 4.5 & 25.06 & 4.5 & 29 \\
\hline 19 & $1 \mathrm{~m} \mathrm{CsCl}$ & 650 & 8 & 186.53 & 3.2 & 147.52 & 5.6 & 39.00 & 6.1 & 36 \\
\hline 20 & $5 \mathrm{~m} \mathrm{CsCl}$ & 650 & 8 & 191.57 & 1.9 & 133.82 & 4.3 & 57.75 & 4.0 & 30 \\
\hline 21 & $\mathrm{H}_{2} \mathrm{O}$ & 650 & 8 & 181.38 & 0.7 & 143.73 & 10.8 & 37.65 & 10.8 & 11 \\
\hline 22 & $1 \mathrm{~m} \mathrm{NaCl}$ & 650 & 8 & 183.02 & 3.9 & 149.85 & 11.9 & 33.17 & 9.0 & 71 \\
\hline 23 & $5 \mathrm{~m} \mathrm{NaCl}$ & 650 & 8 & 199.97 & 2.0 & 170.14 & 11.9 & 29.84 & 11.7 & 45 \\
\hline 24 & $0.1 \mathrm{~m} \mathrm{NaOH}$ & 650 & 12 & 187.09 & 1.9 & 148.63 & 6.0 & 38.46 & 5.3 & 25 \\
\hline 25 & $\begin{array}{l}5 \mathrm{~m} \mathrm{CsCl}+0.1 \mathrm{~m} \\
\mathrm{NaOH}\end{array}$ & 650 & 12 & 194.04 & 7.8 & 130.14 & 11.1 & 63.90 & 4.5 & 24 \\
\hline 26 & $\begin{array}{l}5 \mathrm{~m} \mathrm{NaCl}+0.1 \mathrm{~m} \\
\mathrm{NaOH}\end{array}$ & 650 & 12 & 202.13 & 3.5 & 160.71 & 10.9 & 41.42 & 8.2 & 30 \\
\hline $27^{\mathrm{d}}$ & $\mathrm{H}_{2} \mathrm{O}$ & 700 & 11 & 203.89 & 4.6 & 169.89 & 10.0 & 34.00 & 8.3 & 12 \\
\hline $28^{\mathrm{d}}$ & $0.5 \mathrm{~m} \mathrm{NaOH}$ & 700 & 11 & 223.81 & 11.5 & 180.70 & 8.4 & 43.11 & 10.6 & 10 \\
\hline
\end{tabular}




\begin{tabular}{|c|c|c|c|c|c|c|c|c|c|c|}
\hline$N^{\mathrm{a}}$ & $\begin{array}{l}\text { Composition } \\
\text { studied solution }\end{array}$ & $\begin{array}{l}T \text { run } \\
\left({ }^{\circ} \mathrm{C}\right)\end{array}$ & $\begin{array}{l}t^{\underline{c}} \\
\text { (days) }\end{array}$ & $\begin{array}{l}\text { Th } \\
\left({ }^{\circ} \mathbf{C}\right)\end{array}$ & SD & $\begin{array}{l}\text { Tn } \\
\left({ }^{\circ} \mathrm{C}\right)\end{array}$ & SD & $\begin{array}{l}\text { Th-Tn } \\
\left({ }^{\circ} \mathrm{C}\right)\end{array}$ & SD & $n^{\mathbf{b}}$ \\
\hline $29^{\mathrm{d}}$ & $5 \mathrm{~m} \mathrm{CsCl}$ & 700 & 11 & 226.74 & 3.9 & 171.36 & 3.1 & 55.37 & 3.1 & 11 \\
\hline $30^{\mathrm{d}}$ & $5 \mathrm{~m} \mathrm{CaCl}_{2}$ & 700 & 11 & 265.77 & 2.4 & 213.61 & 6.6 & 52.16 & 5.9 & 9 \\
\hline 31 & $\mathrm{H}_{2} \mathrm{O}$ & 550 & 13 & 143.50 & 1.2 & 94.48 & 23.7 & 49.02 & 23.5 & 28 \\
\hline 32 & $0.1 \mathrm{~m} \mathrm{NaOH}$ & 550 & 13 & 145.70 & 2.5 & 82.25 & 11.5 & 63.45 & 11.6 & 30 \\
\hline 34 & $\mathrm{H}_{2} \mathrm{O}$ & 700 & 13 & 205.05 & 2.4 & 177.28 & 7.0 & 27.76 & 6.7 & 33 \\
\hline 35 & $1 \mathrm{~m} \mathrm{CaCl}_{2}$ & 700 & 13 & 222.23 & 2.9 & 182.99 & 3.7 & 39.23 & 2.0 & 31 \\
\hline 36 & $5 \mathrm{~m} \mathrm{CaCl}_{2}$ & 700 & 13 & 268.83 & 4.3 & 218.83 & 10.9 & 49.99 & 10.9 & 55 \\
\hline 37 & $\mathrm{H}_{2} \mathrm{O}$ & 530 & 13 & 266.69 & 6.4 & 157.19 & 38.8 & 109.50 & 38.8 & 18 \\
\hline 38 & $5 \mathrm{~m} \mathrm{CsCl}$ & 530 & 13 & 135.26 & 2.6 & 21.75 & 29.5 & 113.51 & 29.5 & 10 \\
\hline 39 & $5 \mathrm{~m} \mathrm{CaCl}_{2}$ & 530 & 13 & 178.56 & 4.6 & 125.58 & 10.3 & 52.98 & 9.0 & 14 \\
\hline 40 & $\mathrm{H}_{2} \mathrm{O}$ & 700 & 13 & 215.98 & 5.1 & 183.93 & 5.4 & 32.05 & 8.2 & 17 \\
\hline 41 & $5 \mathrm{~m} \mathrm{NaCl}$ & 700 & 13 & 239.12 & 2.6 & 200.53 & 5.2 & 38.59 & 5.8 & 15 \\
\hline 42 & $5 \mathrm{~m} \mathrm{CsCl}$ & 700 & & 230.44 & 4.5 & 170.03 & 11.6 & 60.41 & 9.0 & 15 \\
\hline
\end{tabular}

${ }^{\mathrm{a}}$ Sample number.

${ }^{\mathrm{b}}$ Number of measured inclusions.

${ }^{\mathrm{c}}$ Run duration.

${ }^{\mathrm{d}}$ Overgrowing method. 